\title{
RECURRENT BACKCROSSING IN THE STUDY OF QUANTITATIVE INHERITANCE
}

\section{J. HILL}

A.R.C. Unit of Biometrical Genetics, Department of Genetics, University of Birmingham

Received 13.v.65

\section{INTRODUCTION}

THE majority of investigations into the inheritance of continuously varying characters using inbred lines have been concentrated exclusively on the $F_{2}$ and subsequent generations in the selfing series, with the result that the potentialities of backcross generations for quantitative inheritance have never been fully explored. True they are usually more difficult to produce than the $F_{2}$, but the extra labour required is

TABLE 1

Scaling tests for the second backcross data of Mather and Vines ( 1946$)$

\begin{tabular}{|c|c|c|}
\hline Test & Flowering time & Final height \\
\hline & & \\
\hline $\mathbf{B}_{11}$ & $2 \cdot 90 \pm \mathbf{1} \cdot 84$ & $-0 \cdot 35 \pm 2 \cdot 55$ \\
$\mathbf{B}_{12}$ & $4 \cdot 32 \pm 1 \cdot 70^{*}$ & $-9 \cdot 64 \pm 2 \cdot 57^{* *}$ \\
$\mathbf{B}_{21}$ & $3 \cdot 66 \pm 1 \cdot 89$ & $-0 \cdot 57 \pm 2 \cdot 86$ \\
$\mathbf{B}_{22}$ & $3 \cdot 60 \pm 2 \cdot 14$ & $-12 \cdot 96 \pm 2 \cdot 95^{* *}$ \\
\hline
\end{tabular}

$* \mathrm{P}=0.05 . \quad * * \mathrm{P}=<0.001$.

amply repaid in the form of additional information both on the components themselves and on the linkage relationships of the genes concerned. Although these generations are not commonly included in biometrical experiments, Mather and Vines (1952) have used them in conjunction with the $F_{2}, F_{3}$ and $F_{4}$ generations to study the inheritance of flowering time and final height in varieties $\mathrm{I}$ and 5 of Nicotiana rustica. Because the experiment containing the recurrent backcross generations gave very heterogeneous second degree statisticsparticularly the covariances-Mather and Vines concluded that their future use in quantitative inheritance must be suspect until such time as further experiments could clarify the situation. Consequently these generations were excluded from their experiments in subsequent years. Mather and Vines did point out however that the performance of the backcross generations might have been affected in some way by their parents having been raised in a glasshouse during the preceding winter. They suggested that such conditions could have produced seed which for developmental reasons was more variable than normal. 
J. HILL

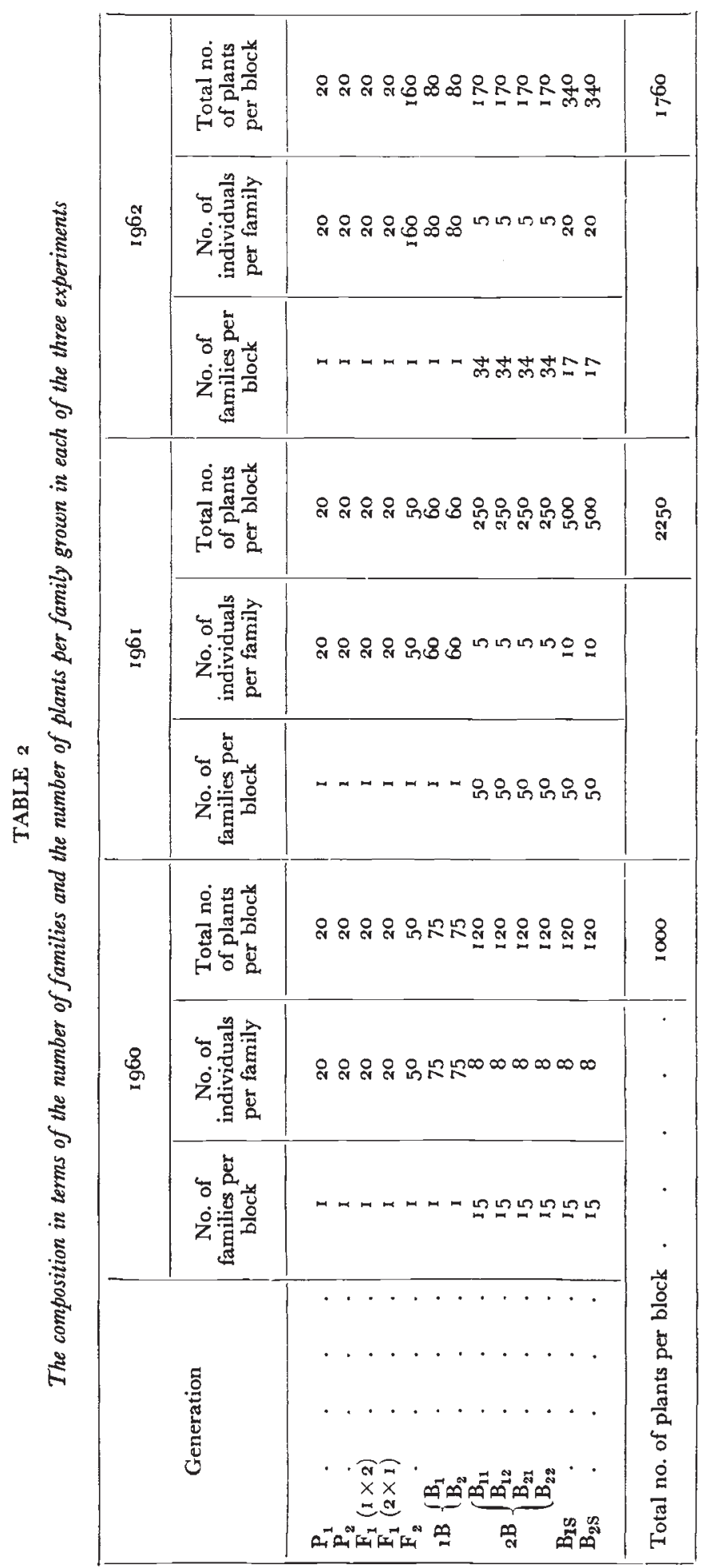


Re-examination of Mather and Vines' data in the light of more recent developments in biometrical genetics makes it possible to glean some further information about the behaviour of recurrent backcrosses. Individual scaling tests similar in nature to the $\mathbf{A}, \mathbf{B}$ and $\mathbf{C}$ tests devised by Mather (1949) reveal only one departure from zero of borderline significance amongst the second backcross generations for flowering time, whereas for height two of them-the $B_{12}$ and $B_{22}$ tests-show highly significant differences from expectation (see tables $I$ and 5 ). This result lends some support to Mather and Vines' suspicions about these generations, at least for one of the characters under investigation. More precise evidence on this point comes from a joint scaling test (see Cavalli, 1952; Jinks, 1955) in which it is possible to fit a model based on weighted least squares estimates of the mid-parent $\mathbf{M}$, additive $[d]$, dominance $[h]$, additive $\times$ additive $[i]$, additive $\times$ dominance $[j]$ and dominance $\times$ dominance $[l]$ parameters to the generation means thereby gaining some insight into the type of genetic system controlling the characters in question. It should be mentioned that these parameters are defined around the $F_{2}$ mean after the mixed metric model devised by Hayman and Mather (1955). The goodness of fit of any particular model can be determined by means of a $\chi^{2}$ test. Re-analysis of the appropriate data in Mather and Vines' experiment reveals the presence of interactions between non-allelic genes for both characters but especially amongst those genes controlling the expression of height. Considering this character first, if the second backcross generations are excluded from the scaling test a model based only on additive and dominance effects is sufficient to fit the remaining data adequately, a result which would seem to implicate the recurrent backcrosses as the chief source of the apparent non-allelic interactions. Turning to flowering time, a simple additive and dominance model does not fit the data satisfactorily even after omission of the second backcross generations. If, however, these generations are retained and the $\mathrm{F}_{3}$ and BIP generations removed instead, such a model can account for the variation observed between the generation means. Thus for flowering time it is these latter generations, not the recurrent backcrosses, which are responsible for the presence of non-allelic interactions. The high covariances between first backcross plants and their second backcross progenies mentioned by Mather and Vines may conceivably be due to a genotype $\times$ environment interaction particularly in view of the fact that the first backcross plants were grown in a glasshouse the preceding winter. Moreover evidence accumulated over the years in connection with other experiments using the backcross generation of $\mathcal{N}$. rustica indicate that with few exceptions they behave normally in respect of both final height and flowering time. Clearly therefore there are no compelling reasons for rejecting backcross generations as being of only limited value in experiments on quantitative characters, though more work is obviously required to assess the usefulness of the second backcross generation. 


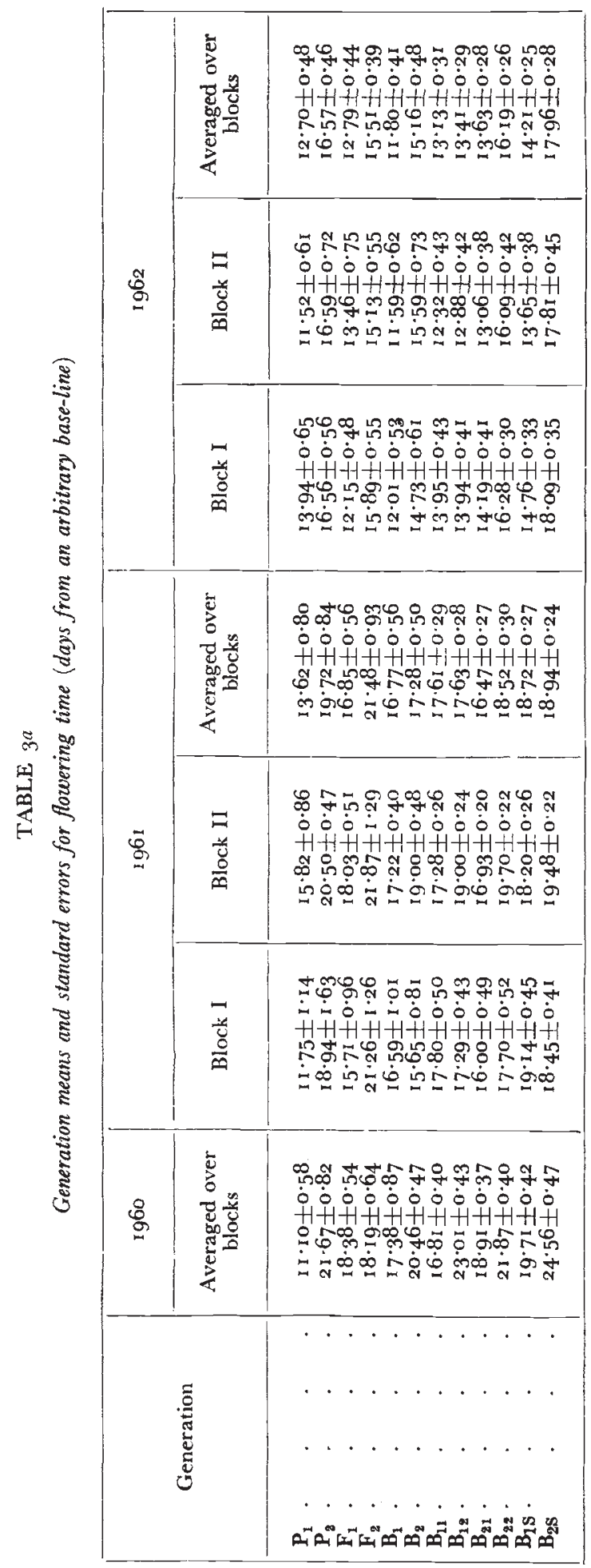




\begin{tabular}{|c|c|c|c|}
\hline \multirow{8}{*}{ 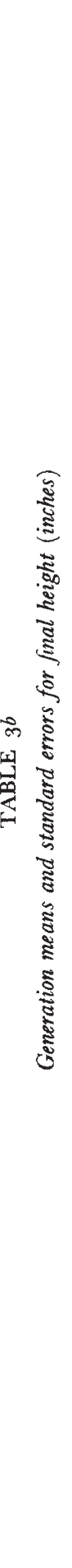 } & \multirow{3}{*}{ ఫ్ర } & 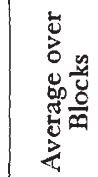 & 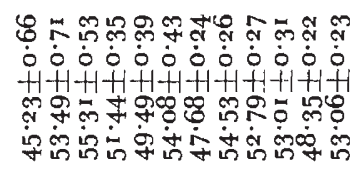 \\
\hline & & 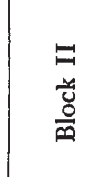 & 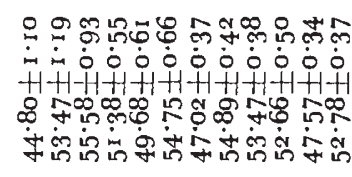 \\
\hline & & 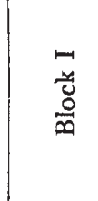 & 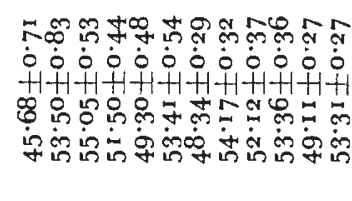 \\
\hline & \multirow{3}{*}{$\stackrel{\mathscr{G}}{\mathscr{G}}$} & 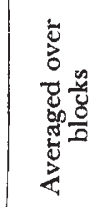 & 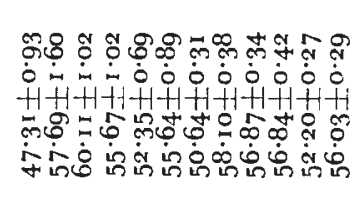 \\
\hline & & 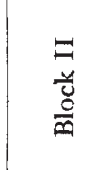 & 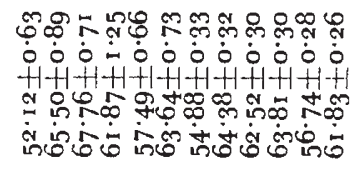 \\
\hline & & 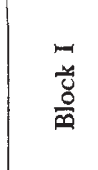 & 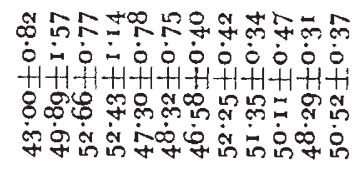 \\
\hline & $\underset{\sigma}{8}$ & 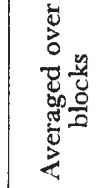 & 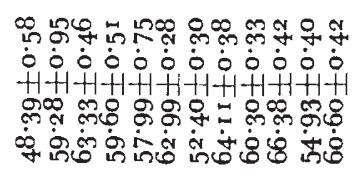 \\
\hline & & .0ّ & $\begin{array}{c}\cdots \\
\cdots \\
\ldots \ldots\end{array} \ldots$ \\
\hline
\end{tabular}


For this reason an experiment with $\mathcal{N}$. rustica which included these generations was initiated in 1960 and repeated in 1961 and 1962 . The present paper describes these experiments in detail and attempts to determine the part which backcross generations can play in studying the inheritance of continuously varying characters.

\section{THE EXPERIMENTAL DESIGN}

The two inbred varieties of $\mathcal{N}$. rustica used in the present experiment were the same two varieties used by Mather and Vines. In all three years, 1960,1961 and 1962 the following generations were grown: $\mathrm{P}_{1}\left(=\mathrm{V}_{\mathrm{I}}\right), \mathrm{P}_{2}\left(=\mathrm{V}_{5}\right), \mathrm{F}_{1}, \mathrm{~F}_{2}, \mathrm{~B}_{1}, \mathrm{~B}_{2}, \mathrm{~B}_{11}, \mathrm{~B}_{12}, \mathrm{~B}_{1 \mathrm{~s}}, \mathrm{~B}_{21}, \mathrm{~B}_{22}$ and $\mathrm{B}_{2 \mathrm{~s}}$. Individual plants chosen at random from amongst the first backcross generations- $B_{1}$ and $B_{2}$-were crossed in turn to both $P_{1}$ and $P_{2}$ and selfed to give the second backcross $\left(\mathrm{B}_{11}, \mathrm{~B}_{12}, \mathrm{~B}_{21}\right.$ and $\left.\mathrm{B}_{22}\right)$ and first backcross selfed $\left(B_{18}\right.$ and $\left.B_{28}\right)$ generations. As will be seen later the use of a common female parent yields additional information about the components of variation. The detailed structure of the experiment is given for all three years in table 2. A randomised block design, in which randomisation was at the level of the individual plant, was employed throughout. In 1960 there were 3 replicates, but in $196 \mathrm{r}$ and 1962 there were only 2 giving 3000,4500 and 3520 , as the total number of plants grown in each year respectively. Because of insufficient glasshouse space the 2 blocks of the $196 \mathrm{I}$ and $\mathrm{r} 962$ experiments had to be sown approximately a month apart. This meant that each block became virtually a separate experiment.

Seeds from the various families were sown in appropriately numbered paper pots containing John Innes No. I compost mixture. Two seeds were sown in each pot and after approximately a fortnight the seedlings were thinned out leaving only the centre plant in each pot. This procedure was adopted in order to minimise the risk of conscious selection. Subsequently the plants were transferred to frames and were finally planted in the experimental field, still in their paper pots, in rows set 27 inches apart with 12 inches between plants within rows. Flowering time in days from an arbitrary date and final height in inches were recorded in all experiments.

\section{THE FIRST DEGREE STATISTICS}

\section{(i) Analysis of variance}

The observed values of all the generation means in all seasons are given together with their standard errors in table 3 . An analysis of variance carried out on these means for the two characters will indicate not only if there are differences between years and generations but also whether the generations respond differently to the external environment (cf. Jinks and Mather, I955). The error for these analyses is derived from the variation between replicate estimates of a generation mean within years. As expected the characters show significant differences between generations and years (table 4$)$. Furthermore it is 
evident that the characters are being controlled by genes showing a differential response to the environment. Closer examination of the data does reveal, however, that for height the genotype $\times$ years (environment) interaction arises chiefly from the anomalous behaviour

TABLE 4

Analysis of variance of the generation means for (a) flowering time and (b) height, (i) for all years and (ii) with the 1960 data excluded

(a) Flowering time

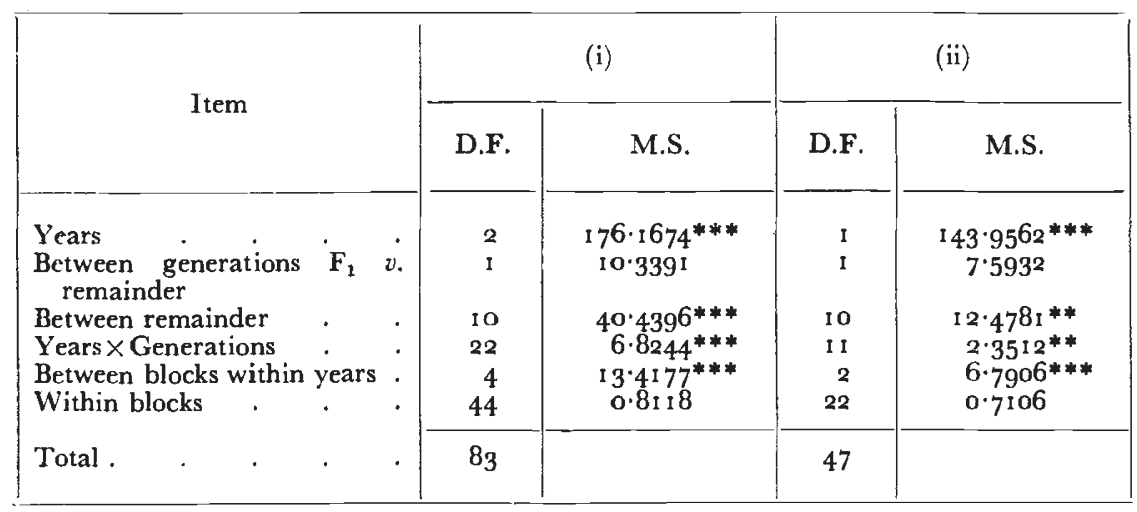

(b) Height

\begin{tabular}{|c|c|c|c|c|}
\hline \multirow{2}{*}{ Item } & \multicolumn{2}{|r|}{ (i) } & \multicolumn{2}{|r|}{ (ii) } \\
\hline & D.F. & M.S. & D.F. & M.S. \\
\hline Years & 2 & $422 \cdot 6623^{* * *}$ & 1 & $162 \cdot 4963^{* * *}$ \\
\hline $\begin{array}{l}\text { Between generations } \\
\text { remainder }\end{array}$ & I & $141 \cdot 2781 * * *$ & 1 & $83 \cdot 7820 * * *$ \\
\hline Between remainder & 10 & 11 $0.3766^{* * *}$ & 10 & $41 \cdot 2127^{* * *}$ \\
\hline Years $\times$ Generations & 22 & $5 \cdot 733^{* * *}$ & II & $1 \cdot 1588$ \\
\hline Between blocks within years & 4 & $214.5732^{* * *}$ & 2 & $407 \cdot 3660^{* * *}$ \\
\hline Within blocks & 44 & I. 4927 & 22 & $2 \cdot 0663$ \\
\hline Total. & 83 & & 47 & \\
\hline
\end{tabular}

** $\mathrm{P}=0.01-0 \cdot 001, \quad * * * \mathrm{P}=<0 \cdot 001$.

of some generations in the I 960 experiment, since exclusion of that year's data renders the interaction non-significant. For flowering time, on the other hand, no one season can be held solely responsible for its significance though the contribution of the I 960 results to the genotype $\times$ environment interaction is disproportionately high. One further point which emerges from this analysis is the significance of the item measuring the differences between the $F_{1}$ and the other generations for height and its non-significance for flowering time. This 
obviously bears upon the question of heterosis and it will be discussed further in a later section.

\section{(ii) Scaling tests}

Scaling tests similar to the A, B and $\mathrm{G}$ tests of Mather have been devised for the second backcross and first backcross selfed generations. The structure of these tests together with the errors to which they are subject are given in table 5. Also included in this table are the expectations of the various tests in terms of the first order interaction parameters $[i],[j]$ and $[l]$ and four second order parameters $[w],[x]$,

\section{TABLE 5}

Scaling tests devised for the generations grown in the experiment together with their appropriate variances and expectations. The standard error for each test is taken as $\sqrt{V}$. Those tests marked with one asterisk are expected to depart most significantly from zero assuming $[\mathrm{i}]=[\mathrm{j}]=[\mathrm{l}]$ and $+([\mathrm{w}]=[\mathrm{x}]=[\mathrm{y}]=[\mathrm{z}])$ and those with two asterisks to depart most significantly if $[\mathrm{i}]=[\mathrm{j}]=[\mathrm{l}]$ and $-([\mathrm{w}]=[\mathrm{x}]=[\mathrm{y}]=[\mathrm{z}])$

\begin{tabular}{|c|c|c|c|}
\hline \multicolumn{2}{|r|}{ Test } & Variance & Expectation \\
\hline A: & $\bar{P}_{1}+F_{1}-2 \bar{B}_{1}$ & $V \overrightarrow{\mathrm{P} 1}+V_{\overrightarrow{\mathrm{F}} 1}+4 \mathrm{~V} \overline{\mathrm{B} 1}$ & $\frac{1}{2}\left([i]-[j]+[l]+\frac{3}{2}[w]-[x]+\frac{1}{2}[y]\right.$ \\
\hline B: & $\mathrm{P}_{2}+\bar{F}_{1}-2 \bar{B}_{2}$ & $\overrightarrow{\mathrm{V} 2}+\overrightarrow{\mathrm{V}} \overline{\mathrm{F} 1}+4 \mathrm{~V} \overrightarrow{\mathrm{B} 2}$ & $\frac{1}{2}([i]+[j]]+[l]-\frac{3}{2}[w]-[x]-\frac{1}{2}[y]$ \\
\hline C: & $\mathrm{P}_{1}+\mathrm{P}_{2}+{ }_{2} \mathrm{~F}_{1}-{ }_{4} \mathrm{~F}_{2}$ & $V \overline{\mathrm{P}_{1}}+\mathrm{V}_{\overline{\mathrm{P} 2}}+4 \mathrm{~V} \overline{\mathrm{F} 1}+16 \mathrm{~V}_{\overline{\mathrm{F}} 2}$ & $2\left([i]+\frac{1}{2}[l]-\frac{1}{2}[x]\right) * *$ \\
\hline $\mathrm{B}_{12}:$ & ${ }_{3} \bar{P}_{1}+F_{1}-4 \bar{B}_{11}$ & $9 \mathrm{~V} \overline{\mathrm{P} 1}+\mathrm{V} \overline{\mathrm{F} 1}+16 \mathrm{~V} \overline{\mathrm{B} 11}$ & $\frac{3}{4}\left([i]-[j]+[l]+\frac{7}{4}[w]-\frac{5}{4}[x]+\frac{3}{4}[y]\right.$ \\
\hline$B_{12}:$ & $\mathrm{P}_{2}+{ }_{3} \mathrm{~F}_{1}-{ }_{4} \bar{B}_{12}$ & $\mathrm{~V} \overline{\mathrm{P} 2}+9 \mathrm{~V} \overline{\mathrm{F} 1}+16 \mathrm{~V} \overline{\mathrm{B} 12}$ & $\frac{3}{4}\left([i]+[j]+[l]-\frac{8}{4}[w]-\frac{3}{4}[x]-1[y]\right.$ \\
\hline$B_{21}:$ & $\mathrm{P}_{1}+{ }_{3} \bar{F}_{1}-4 \bar{B}_{21}$ & $V \overline{P 1}+9 V \overline{F_{1}}+16 V \overline{B 21}$ & $\frac{3}{4}\left([i]-[j]+[l]+\frac{5}{4}[w]-\frac{3}{4}[x]+4[y]\right.$ \\
\hline $\mathrm{B}_{22}:$ & ${ }_{3} \vec{P}_{2}+F_{1}-{ }_{4} \bar{B}_{22}$ & $9 \mathrm{~V} \overline{\mathrm{P} 2}+\mathrm{V} \overline{\mathrm{F} 1}+16 \mathrm{~V} \overline{\mathrm{B} 22}$ & $\frac{8}{4}\left([i]+[j]+[l]-\frac{7}{4}[w]-\frac{5}{4}[x]-\frac{3}{4}[y]\right.$ \\
\hline $\mathrm{B}_{1 \mathrm{~S}}:$ & ${ }_{5} \overline{\mathrm{P}}_{1}+{ }_{2} \overline{\mathrm{F}}_{1}+\overline{\mathrm{P}}_{2}-8 \mathrm{~B}_{1} \mathrm{~s}$ & ${ }_{25} \mathrm{~V} \overline{\mathrm{P}}+{ }_{4} \mathrm{~V} \overline{\mathrm{F1}}+\mathrm{V} \overline{\mathrm{P} 2}+6{ }_{4} \mathrm{~V} \overline{\mathrm{B1S}}$ & $2\left(2[i]-\frac{1}{8}[j]+\frac{3}{3}[l]+\frac{3}{2}[w]-\frac{5}{4}[x]+\frac{3}{8}[y]\right.$ \\
\hline$B_{2 S}:$ & ${ }_{5} \bar{P}_{2}+{ }_{2} \bar{F}_{1}+\bar{P}_{1}-8 \bar{B}_{2} S$ & ${ }_{25} \mathrm{VP}_{\bar{P} 2}+{ }_{4} \mathrm{~V}_{\overline{\mathrm{F}} 1}+\mathrm{V}_{\overline{\mathrm{P}} 1}+6{ }_{4} \mathrm{~V}_{\overline{\mathrm{B} 2 \mathrm{~S}}}$ & $\begin{array}{l}2\left(2[i]+\frac{1}{2}[j]+3[l]-\frac{3}{2}[w]-\frac{5}{4}[x]-\frac{3}{8}[y]\right. \\
\left.\quad-\frac{3}{16}[z]\right)\end{array}$ \\
\hline
\end{tabular}

For definition of $[w],[x],[y]$ and $[z]$ see text and table 7 .

$[y]$ and $[z]$ which will be defined more precisely at a later stage. The object of these individual scaling tests is to pick out those generations which are exhibiting non-allelic interactions, although the fact that a particular test does not depart significantly from zero is not necessarily conclusive proof of their absence from a given generation (see tables 5 and 6). It is clear, however, that both characters are controlled by interacting genes. Moreover the results of identical tests are not always homogeneous over seasons or even between blocks within seasons. Such differences are normally indicative of genotype $\times$ environment interactions and hence they corroborate the results of the analysis of variance. Overall, both characters are more or less equally susceptible 

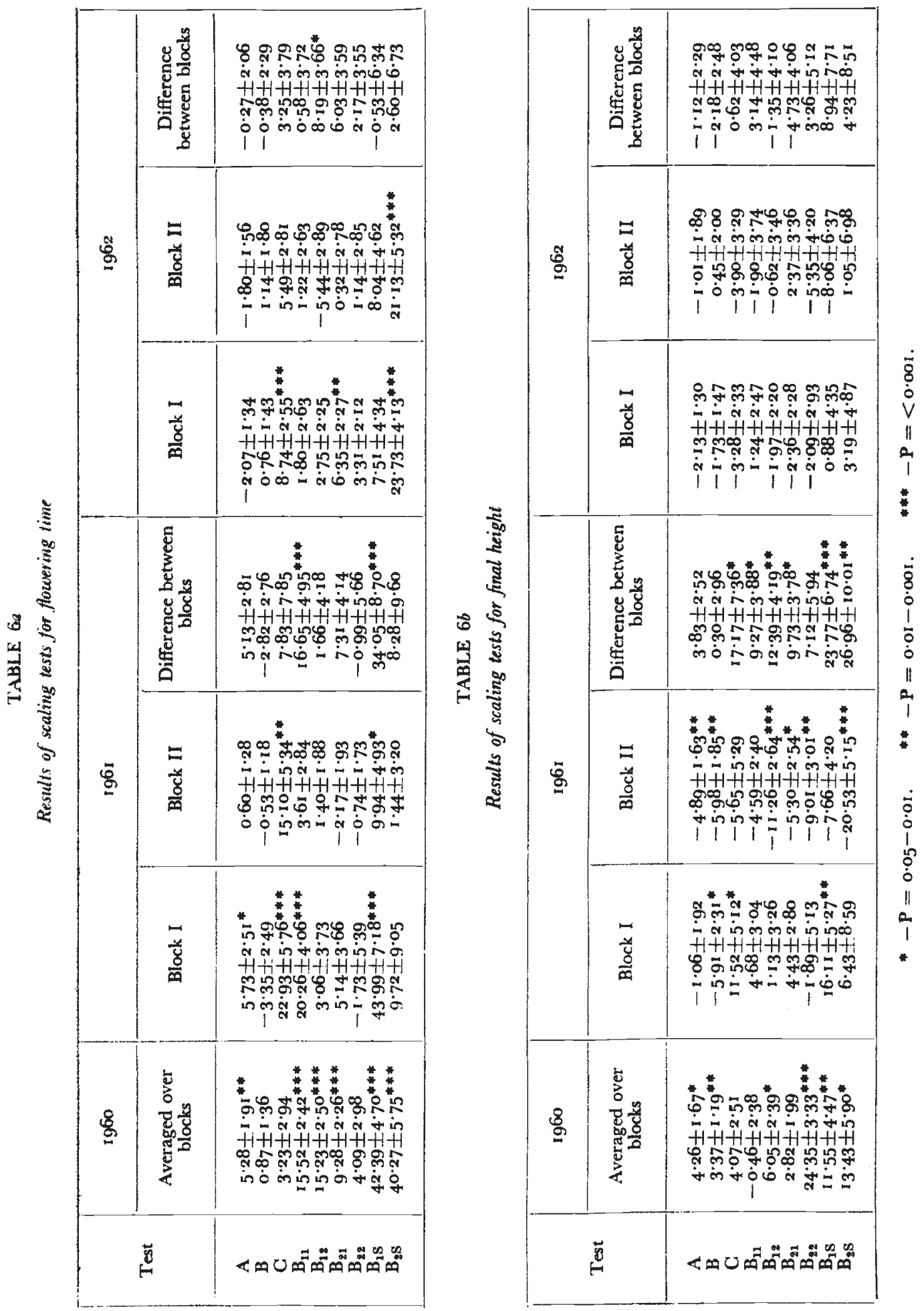
to non-allelic and environmental interactions, although these tests do suggest a virtual absence of any interactions for height in I962.

A more comprehensive picture of the genetic systems involved in the control of these two characters can be obtained from the joint scaling test of Cavalli (1952). Because twelve different generations were grown in this experiment, it was possible to fit not only the parameters $\mathbf{M},[d],[h],[i],[j]$ and $[l]$ measuring the main effects and first order interactions of the genes concerned, but also four additional parameters $[w],[x],[y]$ and $[z]$ estimating the second order interactions between additive $\times$ additive $\times$ additive, additive $\times$ additive $\times$

TABLE 7

Expectations of the generation means in terms of $M,[\mathrm{~d}]$, $[\mathrm{h}],[\mathrm{i}],[\mathrm{j}],[\mathrm{l}],[\mathrm{w}],[\mathrm{x}],[\mathrm{y}]$ and $[\mathrm{z}]$

\begin{tabular}{|c|c|c|c|c|c|c|c|c|c|c|}
\hline \multirow{2}{*}{ Generation } & \multicolumn{10}{|c|}{ Coefficients of: } \\
\hline & $\mathbf{M}$ & {$[d]$} & {$[h]$} & [i] & {$[j]$} & {$[l]$} & {$[w]$} & {$[x]$} & {$[y]$} & {$[z]$} \\
\hline$P_{1}$ & I & 1 & $\ldots$ & I & $-\frac{1}{2}$ & $\frac{1}{4}$ & I & $-\frac{1}{2}$ & $\frac{1}{4}$ & $-\frac{1}{8}$ \\
\hline $\mathrm{P}_{2}$ & I & $-I$ & $\ldots$ & I & $\frac{1}{2}$ & $\frac{1}{4}$ & $-I$ & $-\frac{1}{2}$ & $-\frac{1}{4}$ & $-\frac{i}{8}$ \\
\hline $\mathrm{F}_{1}$ & I & $\ldots$ & I & $\cdots$ & $\ldots$ & $\frac{1}{4}$ & $\cdots$ & ... & $\ldots$ & $\frac{1}{8}$ \\
\hline $\mathrm{F}_{2}$ & I & $\cdots_{1}$ & $\frac{1}{2}$ & $\dddot{t}$ & $\cdots$ & $\cdots$ & $\cdots_{1}$ & $\cdots$ & $\cdots$ & $\cdots$ \\
\hline $\begin{array}{l}B_{1} \\
B_{2}\end{array}$ & $\begin{array}{l}\text { I } \\
\text { I }\end{array}$ & $-\frac{\frac{1}{2}}{2}$ & $\frac{1}{2}$ & $\frac{4}{4}$ & $\begin{array}{l}\cdots \\
\cdots\end{array}$ & $\cdots$ & $\begin{array}{r}\frac{1}{8} \\
-\frac{1}{8}\end{array}$ & $\begin{array}{l}* \\
. .\end{array}$ & $\begin{array}{l}\cdots \\
\ldots\end{array}$ & $\begin{array}{l}\cdots \\
\ldots\end{array}$ \\
\hline $\mathrm{B}_{11}$ & I & $\frac{2}{4}$ & $\frac{1}{4}$ & $\frac{8}{18}$ & $-\frac{3}{18}$ & $\frac{1}{16}$ & $\frac{27}{84}$ & $-\frac{8}{64}$ & $\frac{3}{64}$ & $-\frac{1}{84}$ \\
\hline $\mathrm{B}_{22}$ & I & $-\frac{3}{1}$ & $\frac{1}{3}$ & $\frac{\frac{8}{16}}{-1}$ & $\frac{\frac{3}{16}}{1 .}$ & $\frac{1}{16}$ & $\begin{array}{l}-\frac{27}{64} \\
-\frac{1}{4}\end{array}$ & $-\frac{9}{64}$ & $-\frac{-3}{64}$ & $-\frac{1}{64}$ \\
\hline $\begin{array}{l}\mathrm{B}_{21} \\
\mathrm{~B}_{12}\end{array}$ & I & $-\frac{4}{4}$ & $\frac{4}{3}$ & $\begin{array}{l}18 \\
\frac{1}{18}\end{array}$ & $\begin{array}{r}\frac{1}{16} \\
-\frac{1}{16}\end{array}$ & $\frac{\frac{1}{16}}{\frac{1}{16}}$ & $\begin{array}{r}\frac{-1}{64} \\
-\frac{1}{64}\end{array}$ & $\frac{\frac{1}{64}}{\frac{1}{64}}$ & $\begin{array}{r}\frac{84}{64} \\
-\frac{1}{64}\end{array}$ & $\frac{\frac{1}{64}}{\frac{1}{64}}$ \\
\hline $\mathrm{B}_{1 \mathrm{~S}}$ & I & $\frac{1}{2}$ & $\frac{4}{4}$ & $\frac{1}{4}$ & $-\frac{1}{8}$ & $\frac{1}{16}$ & $\frac{1}{8}$ & $-\frac{1}{16}$ & $\frac{\frac{1}{32}}{32}$ & $-\frac{1}{64}$ \\
\hline $\mathrm{B}_{2 \mathrm{~S}}$ & I & $-\frac{1}{2}$ & $\frac{1}{4}$ & $\frac{1}{4}$ & & $\frac{1}{16}$ & $-\frac{1}{8}$ & $-\frac{1}{18}$ & $-\frac{1}{32}$ & $-\frac{1}{64}$ \\
\hline
\end{tabular}

dominance, additive $\times$ dominance $\times$ dominance and dominance $\times$ dominance $\times$ dominance respectively. For comparison with van der Veen's $\theta$ notation (1959) $w=i_{a b c}\left|, x=j_{a b}\right|_{c}, y=\left.j_{a}\right|_{b c}$ and $z=\left.l\right|_{a b c}$. Expectations for the twelve generations in terms of these ten parameters are given in table 7. Clearly the results of the joint scaling tests merely confirm previous results in indicating the presence of non-allelic interactions amongst the genes governing both characters (table 8). By successively fitting appropriate models to the data it is possible to gauge the importance of the first order and second order interaction effects in relation to the main effects of the genes concerned. For example, by initially fitting a model based on $\mathbf{M},[d]$ and $[h]$ and then one depending upon $\mathbf{M},[d],[h],[i],[j]$ and $[l]$ to the same data, the improvement in the goodness of fit of the latter model over the former will show whether $[i],[j]$ and $[l]$ jointly account for a significant amount of the variation present amongst the generation means. Again the evidence points overwhelmingly to the presence of interacting genes (table 9). Indeed it appears that even the more complex interactions embracing sets of three genes occur quite frequently. 

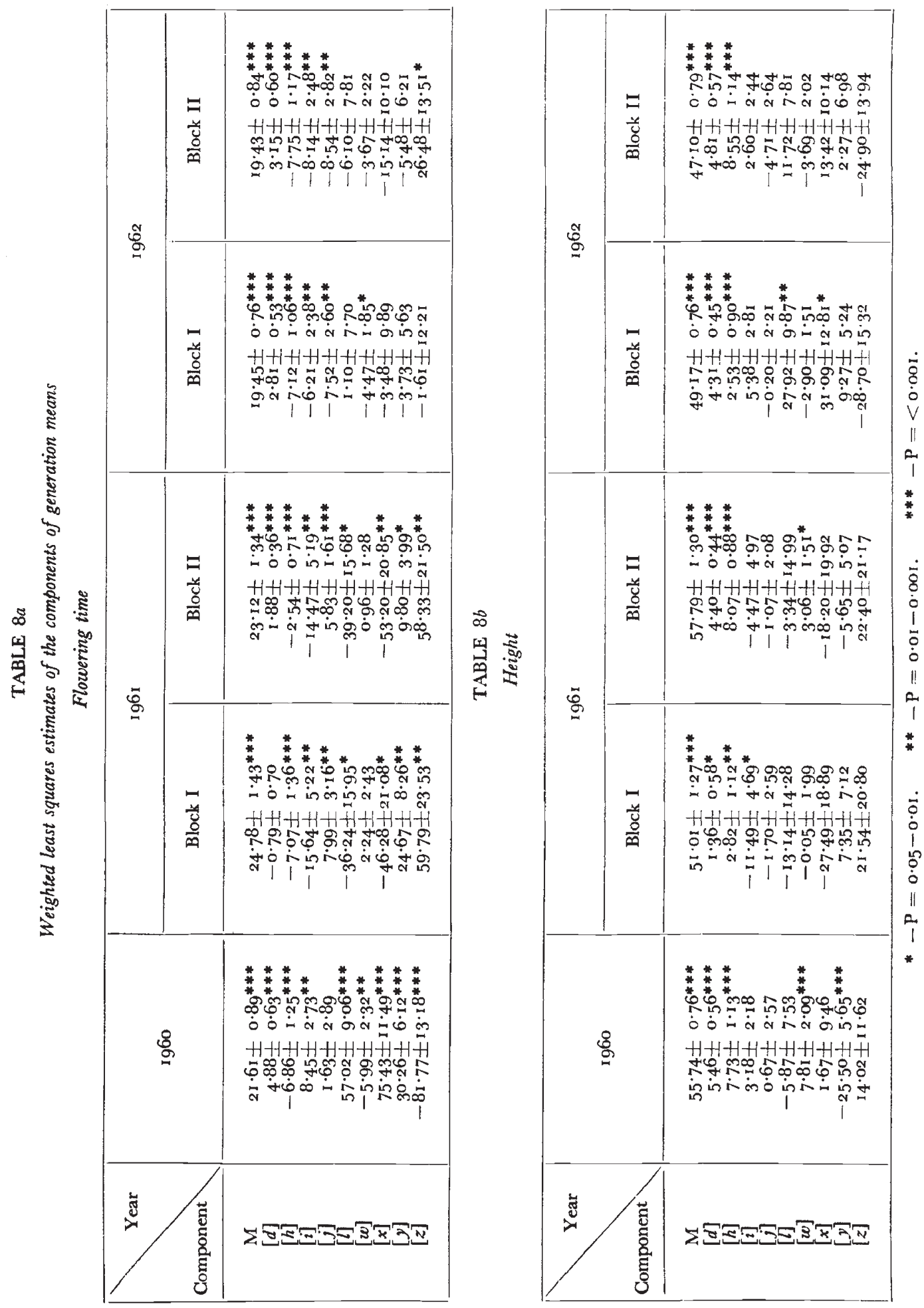
This is perhaps not surprising in view of the many genes which must be concerned with the expression of flowering time and final height, although there are of course numerous crosses between other $\mathcal{N}$. rustica varieties in which these two characters show no evidence of interactions (see Jinks and Morley Jones, 1958). Whilst it is not possible

\section{TABLE $9 a$}

Significance levels of the main effects [d] and [h], the first order interactions $[\mathrm{i}],[\mathrm{j}]$ and $[\mathrm{l}]$ and second order interactions $[\mathrm{w}],[\mathrm{x}],[\mathrm{y}]$ and $[\mathrm{z}]$

Flowering time

\begin{tabular}{|c|c|c|c|c|c|c|}
\hline \multirow{2}{*}{ Parameters } & \multirow{2}{*}{ D.F. } & \multirow{2}{*}{$\chi^{2}$ for 1960} & \multicolumn{2}{|c|}{ I $96 !$} & \multicolumn{2}{|c|}{1962} \\
\hline & & & Block I & Block II & Block I & Block II \\
\hline $\begin{array}{l}{[d] \text { and }[h]} \\
{[i],[j] \text { and }[l]} \\
{[w],[x],[y] \text { and }[z]} \\
\text { Remainder }\end{array}$ & $\begin{array}{l}2 \\
3 \\
4 \\
2\end{array}$ & $\begin{array}{l}329 \cdot 53^{* * * *} \\
84^{* 0} 039^{* * *} \\
66.855^{* * *} \\
21 \cdot 84^{* * *}\end{array}$ & $\begin{array}{l}13 \cdot 4^{1} 4^{* *} \\
26 \cdot 455^{* * *} \\
27 \cdot 307^{* * *} \\
4.984\end{array}$ & $\begin{array}{l}157 \cdot 779^{* * *} \\
10 \cdot 307^{*} \\
19 \cdot 737^{* * *} \\
0.504\end{array}$ & $\begin{array}{l}134 \cdot 134^{* * *} \\
32 \cdot 33^{* * *} \\
14 \cdot 3^{8} 5^{* *} \\
13 \cdot 201^{* *}\end{array}$ & $\begin{array}{l}129 \cdot 175^{* * *} \\
40 \cdot 434^{* * *} \\
5 \cdot 308 \\
5 \cdot 721\end{array}$ \\
\hline
\end{tabular}

TABLE $9^{b}$

Height

\begin{tabular}{|c|c|c|c|c|c|c|}
\hline \multirow{2}{*}{ Parameters } & \multirow{2}{*}{ D.F. } & \multirow{2}{*}{$\chi^{2}$ for 1960} & \multicolumn{2}{|c|}{$196 \mathrm{I}$} & \multicolumn{2}{|c|}{1962} \\
\hline & & & Block I & Block II & Block I & Block II \\
\hline $\begin{array}{l}{[d] \text { and }[h]} \\
{[i],[j] \text { and }[l]} \\
{[w],[x],[y] \text { and }[z]} \\
\text { Remainder }\end{array}$ & $\begin{array}{l}2 \\
3 \\
4 \\
2\end{array}$ & $\begin{array}{c}\mathrm{r} 626 \cdot 5 \mathrm{r} 6^{* * * *} \\
0 \cdot 806 \\
40 \cdot 45^{* * *} \\
46 \cdot 557^{* * *}\end{array}$ & $\begin{array}{c}207 \cdot 835^{* * *} \\
20 \cdot 557^{* * *} \\
5 \cdot 692 \\
14.865^{* * *}\end{array}$ & $\mid \begin{array}{c}145 \cdot 102^{* * *} \\
22 \cdot 722^{* * *} \\
6 \cdot 13^{6} \\
1 \cdot 430\end{array}$ & $\begin{array}{l}4^{80} \cdot 664^{* * *} \\
5 \cdot 094 \\
5 \cdot 283 \\
3 \cdot 037\end{array}$ & $\begin{array}{l}466 \cdot 55^{6 * * *} \\
1 \cdot 123 \\
4 \cdot 317 \\
5 \cdot 85^{1}\end{array}$ \\
\hline
\end{tabular}

* $-\mathrm{P}=0.05-0.01 . \quad$ ** $-\mathrm{P}=0.01-0.001 . \quad * * *-\mathrm{P}=<0.001$.

to draw firm conclusions on this point, it does appear from the significance levels of these components over the different seasons that non-allelic interactions figure more prominently in the expression of flowering time than they do for height.

\section{(iii) Components of heterosis}

From the weighted least squares estimates of the components of the generation means it is possible to predict the effects of heterosis and compare this expectation with the value calculated directly from the mean observed for parental and $F_{1}$ generations. Adopting the definition of heterosis used by Jinks and Morley Jones (1958), that is the difference between the mean of the $F_{1}$ generation and that of its better parent $\left(\mathrm{P}_{0}\right)$, the measure of heterosis $F_{1}-\bar{P}_{0}=\mid[h]+\frac{1}{4}[l]$ 
$+\frac{1}{8}[z]|-|[d]+[i]-\frac{1}{2}[j]+\frac{1}{4}[l]+[w]-\frac{1}{2}[x]+\frac{1}{4}[y]-\frac{1}{8}[z] \mid$, which equals $\left|[h]-[i]+\frac{1}{2}[x]+\frac{1}{4}[z]\right|-\left|[d]-\frac{1}{2}[j]+[w]+\frac{1}{4}[y]\right|$. Previous analysis has already shown that for flowering time the $F_{1}$ mean is not significantly different from the means of the remaining generations and, moreover, since the $F_{1}$ mean generally lies within the parental range there can be no heterosis for this character. For height, on the other hand, the $F_{1}$ is consistently superior to the better parent, although this difference generally fails to reach significance at the 5 per cent. level of probability (table Io). It is noticeable that in I960, when the effects of heterosis are most marked, non-allelic interactions play a more important part in the expression of this character, thus tending to confirm the finding of Jinks and Morley Jones that interactions are a major source of heterosis, although as the flowering time results demonstrate interactions do not inevitably give rise to heterosis.

TABLE Io

The components of heterosis for height

\begin{tabular}{|c|c|c|c|c|c|}
\hline \multirow[t]{2}{*}{ Season } & \multirow{2}{*}{1960} & \multicolumn{2}{|c|}{1961} & \multicolumn{2}{|c|}{$19^{62}$} \\
\hline & & Block I & Block II & Block I & Block II \\
\hline $\begin{array}{l}\left|[h]-[i]+\frac{1}{4}[x]+\frac{d}{2}[z]\right| \\
-\mid[d]+\frac{1}{d}[j]+[w]\end{array}$ & $-\left|\begin{array}{l}8.89 \\
7.23\end{array}\right|$ & $-\left|\begin{array}{l}5 \cdot 95 \\
2 \cdot 30\end{array}\right|$ & $-\left|\begin{array}{l}9.04 \\
5.52\end{array}\right|$ & $-\left|\begin{array}{l}5 \cdot 52 \\
3 \cdot 63\end{array}\right|$ & $\left|\begin{array}{r}\mid 6 \cdot 43 \\
-|-0.67|\end{array}\right|$ \\
\hline $\begin{array}{l}\text { Predicted heterosis } \\
\text { Observed heterosis } \\
\left(\mathrm{F}_{1}-\mathrm{P}_{2}\right)\end{array}$ & $\begin{array}{c}1 \cdot 66 \\
4 \cdot 05 \pm 1 \cdot 05^{* * *}\end{array}$ & $\begin{array}{c}3 \cdot 65 \\
2 \cdot 77 \pm 1 \cdot 75\end{array}$ & $\begin{array}{c}3 \cdot 52 \\
2 \cdot 26 \pm 1 \cdot 15^{*}\end{array}$ & $\begin{array}{l}1 \cdot 89 \\
1 \cdot 55 \pm 0 \cdot 98\end{array}$ & $\begin{array}{c}7 \cdot 10 \\
2 \cdot 09 \pm 1 \cdot 51\end{array}$ \\
\hline
\end{tabular}

$*-P=0.05-0.01 . \quad * * *-P=<0.001$.

With regard to the type of genetic systems controlling these two characters it is, as Jinks and Morley Jones point out, difficult to make inferences about the kind of interaction from the magnitude of the estimates. In practice the classification of interacting systems must therefore depend on the relative signs of these components, particularly those which are unaffected by the degree of association $(r)$. Of the components $[d],[h],[i],[j]$ and $[l]$ Jinks and Morley Jones have shown that only $[h]$ and $[l]$, that is those depending solely on dominance effects, are independent of the degree of association. This system can be extended to cover interactions between sets of three genes. Assuming that the parents $\mathbf{P}_{1}$ and $\mathbf{P}_{2}$ differ at $k$ loci and that of these $\mathbf{P}_{2}$ has $k^{\prime}$ of greater effect then of the $\frac{1}{8} k(k-1)(k-2)$ possible combinations of three genes, $\frac{1}{8} k-k^{\prime}\left(k-k^{\prime}-1\right)\left(k-k^{\prime}-2\right)$ sets have 3 genes of increasing effect in $\mathrm{P}_{1}, \frac{1}{6} k^{\prime}\left(k^{\prime}-1\right)\left(k^{\prime}-2\right)$ sets are between 3 decreasing genes, $k^{\prime}\left[\frac{1}{2}\left(k-k^{\prime}\right)\left(k-k^{\prime}-I\right)\right]$ are between 2 increasing genes and I decreasing gene and $k-k^{\prime}\left[\frac{1}{2}\left(k^{\prime}\right)\left(k^{\prime}-I\right)\right]$ are combinations involving I increasing 
gene and 2 decreasing genes. Considering only $[w],[x],[y]$ and $[z]$, the two parental means can be written as

$$
\begin{aligned}
P_{1}= & \pm\left[\frac{1}{8} k(k-1)(k-2)-\frac{1}{6} k^{\prime}\left(k^{\prime}-1\right)\left(k^{\prime}-2\right)-\frac{1}{2} k^{\prime}\left(k-k^{\prime}\right)\left(k-k^{\prime}-\mathrm{I}\right)\right] w \\
P_{2} & \mp\left[\frac{1}{8} k^{\prime}\left(k^{\prime}-1\right)\left(k^{\prime}-2\right)+\frac{1}{2} k^{\prime}\left(k-k^{\prime}\right)\left(k-k^{\prime}-1\right)\right] w-\frac{1}{2}\left[\frac{1}{2}\left(k-k^{\prime}\right)\right. \\
& \left.\left(k-k^{\prime}-1\right)(k-2)+\frac{1}{2} k^{\prime}(k-1)(k-2)-k^{\prime}\left(k-k^{\prime}\right)(k-2)\right] x \pm 1\left[\left(k-k^{\prime}\right)\right. \\
& \left.\frac{1}{2} k(k-1)-\left(k^{\prime}\right) \frac{1}{2} k(k-1)\right] y-\frac{1}{8}\left[\frac{1}{8} k(k-1)(k-2)\right] z .
\end{aligned}
$$

If $r$ is put equal to $\mathrm{I}-\frac{2 k^{\prime}}{k}$ (see Jinks and Morley Jones) this becomes

$$
\bar{P}_{1}= \pm r\left[\Sigma w+k^{3}\left(r^{2}-1\right)\right]-\frac{1}{2} \frac{k r^{2}-1}{k-1} \Sigma x \pm r \Sigma \frac{1}{4} y-\Sigma \frac{1}{8} z .
$$

The coefficients in front of the parameters derive from the fact that in the mixed metric model of Hayman and Mather the interactions are defined around the $\mathrm{F}_{2}$ generation mean. Not surprisingly only $[z]$ amongst the second order parameters remains unaffected by the degree of association.

With sets of 3 interacting genes it is possible to specify the relationships between the components of generation means so as to yield genetic ratios corresponding to those expected on the basis of interactions in the classical Mendelian sense. This classification is merely an extension of the one devised by Hayman and Mather covering interactions between pairs of non-allelic genes. Since the classification of the gene system must depend primarily on the relative signs of the first and second order parameters both in relation to each other and to the main effects, the interacting systems fall into four main categories which can be defined as follows:

(i) $d=h=\frac{3}{2}\left[i=j=l=\frac{3}{2}(w=x=y=z)\right]$;

(ii) $d=h=-\frac{1}{2}\left[i=j=l=-\frac{1}{2}(w=x=y=z)\right]$;

(iii) $d=h=-\frac{3}{2}\left[i=j=l=\frac{1}{2}(w=x=y=z)\right]$ and finally

(iv) $d=h=\frac{1}{4}[i=j=l=-(w=x=y=z)]$.

Of these four basic types the first is a classical complementary interaction requiring the presence of all three genes and which yields a 27:37 ratio in the $F_{2}$ generation. The second is a duplicate interaction giving a 63:I ratio in the $F_{2}$; the third requires that at least two genes be present for an interaction to occur but that the addition of the third gene has no effect. This gives a 54:10 ratio in the $F_{2}$, whilst the last type yields a duplicate interaction for the first two genes with the third gene having an effect over and above that of the first two thereby giving an $F_{2}$ ratio of $27: 36: 1$.

Remembering that of the parameters only $[h],[l]$ and $[z]$ are independent of the degree of association and considering flowering time first, in $1960[h]$ and $[z]$ are both significantly negative whilst $[l]$ is significantly positive, which is indicative of a duplicate type interaction between sets of three genes. In 1961 and 1962 , on those occasions when these three parameters are significant, $[h]$ and $[l]$ take the same 
sign but $[z]$ is now positive. This situation appears to square with a duplicate type interaction for the first two genes with the presence of the third gene producing an additional response. It would seem therefore that flowering time is controlled in the main by genes which show a preponderance of duplicate type interactions. This conclusion is borne out by the results, since in 1960 and $196 \mathrm{I}$, when these components are significant, the majority of the generations have a mean flowering time greater than the mid-parent, that is closer to $\mathbf{P}_{2}$ the later flowering parent than $P_{1}$ (see table 3 ). For height, on the other hand, little can be said about the type of interactions which occur if only because of the insignificance of the interaction parameters, particularly $[l]$ and $[z]$. Indeed it is obvious from table 9 that the interactions as a whole account for a much smaller amount of the variation relative to the main effects than they do for flowering time. At first sight these results may appear to conflict in that despite the prevalence of interactions for flowering time it does not show any heterosis. But heterosis can only arise through the action of dispersed complementary genes, whereas the tests indicate that the interactions are chiefly of a duplicate type for flowering time and duplicate interactions cannot result in heterosis.

To summarise, both characters are controlled by genes which, besides showing additivity and dominance, interact amongst themselves and with the external environment, although the evidence does suggest that height is perhaps less affected by such interactions than flowering time. Heterosis is absent for flowering time, whilst it only proves to be of significance for height in that season when interactions are most widespread even though the $F_{1}$ generation is consistently taller than the better parent.

\section{THE SECOND DEGREE STATISTICS}

(i) Non-segregating generations

Variation within non-segregating generations must be environmental in origin and therefore any heterogeneity amongst these variances will reflect a lack of stability on the part of that particular generation in its response to different environments. The homogeneity of these variances within and between seasons can be readily tested by means of a Bartlett test, from which it is apparent that height is the more stable of the two characters (table II). There is no evidence to suggest that the $F_{1}$ is any more stable than either of the inbred lines. On the contrary, there is every reason to believe that overall it is less stable than $P_{1}$ and possibly $P_{2}$ also. This view supports the conclusions reached by Jinks and Mather (I955) namely that in $\mathcal{N}$. rustica flowering time was the least stable of all the characters which they examined and that the $F_{1}$ was no more stable than the parents.

(ii) Unweighted estimation of the components of variance

Thus far we have only been concerned with estimating those components pertaining to generation means. However, to obtain a 
clearer picture of the respective roles of dominance and linkage it is necessary to turn to the components of the second degree statisticsvariances and covariances. Excluding linkage for the moment and assuming the absence of non-allelic interactions, it is possible to define

TABLE I $a$

Variances of the non-segregating generations for flowering time over blocks and seasons

\begin{tabular}{|c|c|c|c|c|c|c|}
\hline \multirow[t]{2}{*}{ Generation } & \multicolumn{2}{|c|}{$P_{1}$} & \multicolumn{2}{|c|}{$P_{2}$} & \multicolumn{2}{|c|}{$F_{1}$} \\
\hline & D.F. & M.S. & D.F. & M.S. & D.F. & M.S. \\
\hline I960 $\left\{\begin{array}{l}\text { Block I } \\
\text { Block II } \\
\text { Block III }\end{array}\right.$ & $\begin{array}{l}18 \\
19 \\
19\end{array}$ & $\begin{array}{r}7 \cdot 10 \\
19 \cdot 06 \\
30 \cdot 03\end{array}$ & $\begin{array}{l}19 \\
19 \\
19\end{array}$ & $\begin{array}{l}30 \cdot 83 \\
34 \cdot 66 \\
55 \cdot 10\end{array}$ & $\begin{array}{l}39 \\
39 \\
39\end{array}$ & $\begin{array}{l}36 \cdot 66 \\
33: 34 \\
31 \cdot 55\end{array}$ \\
\hline 196r $\left\{\begin{array}{l}\text { Block I } \\
\text { Block II : }\end{array}\right.$ & $\begin{array}{l}19 \\
16\end{array}$ & $\begin{array}{l}25 \cdot 7^{8} \\
12 \cdot 65\end{array}$ & $\begin{array}{l}17 \\
17\end{array}$ & $\begin{array}{r}47 \cdot 70 \\
3 \cdot 91\end{array}$ & $\begin{array}{l}37 \\
36\end{array}$ & $\begin{array}{r}35 \cdot 08 \\
9 \cdot 75\end{array}$ \\
\hline I962 $\left\{\begin{array}{l}\text { Block I } \\
\text { Block II }\end{array}\right.$. & $\begin{array}{l}17 \\
18\end{array}$ & $\begin{array}{l}7.59 \\
7.04\end{array}$ & $\begin{array}{l}17 \\
16\end{array}$ & $\begin{array}{l}5.67 \\
8.83\end{array}$ & $\begin{array}{l}38 \\
36\end{array}$ & $\begin{array}{r}8 \cdot 87 \\
20 \cdot 64\end{array}$ \\
\hline $\begin{array}{c}\text { Heterogeneity } \\
\chi^{2}\end{array}\left\{\begin{array}{l}\text { Within seasons } \\
\text { Between seasons }\end{array}\right.$ & $\begin{array}{l}4 \\
2\end{array}$ & $\begin{aligned} 11 \cdot 67^{*} \\
8 \cdot 61^{*}\end{aligned}$ & $\begin{array}{l}4 \\
2\end{array}$ & $\begin{array}{l}23.83^{* * * *} \\
22.57^{* * *}\end{array}$ & $\begin{array}{l}4 \\
2\end{array}$ & $\begin{array}{l}19 \cdot 64^{* * *} \\
14 \cdot 28^{* * *}\end{array}$ \\
\hline
\end{tabular}

TABLE II $b$

Height

\begin{tabular}{|c|c|c|c|c|c|c|}
\hline \multirow[t]{2}{*}{ Generation } & \multicolumn{2}{|c|}{$P_{1}$} & \multicolumn{2}{|c|}{$\mathbf{P}_{2}$} & \multicolumn{2}{|c|}{$F_{1}$} \\
\hline & D.F. & M.S. & D.F. & M.S. & D.F. & M.S. \\
\hline $1960\left\{\begin{array}{l}\text { Block I } \\
\text { Block II } \\
\text { Block III }\end{array}\right.$ & $\begin{array}{l}18 \\
19 \\
19\end{array}$ & $\begin{array}{r}30 \cdot 98 \\
20 \cdot 37 \\
9 \cdot 4^{2}\end{array}$ & $\begin{array}{l}19 \\
19 \\
19\end{array}$ & $\begin{array}{l}70 \cdot 57 \\
49.40 \\
27.69\end{array}$ & $\begin{array}{l}39 \\
39 \\
39\end{array}$ & $\begin{array}{l}39 \cdot 58 \\
16 \cdot 59 \\
19 \cdot 94\end{array}$ \\
\hline r96 I $\left\{\begin{array}{l}\text { Block I } \\
\text { Block II }\end{array}\right.$ & $\begin{array}{l}18 \\
16\end{array}$ & $\begin{array}{r}12 \cdot 7^{8} \\
6 \cdot 74\end{array}$ & $\begin{array}{l}17 \\
17\end{array}$ & $\begin{array}{l}44 \cdot 46 \\
15 \cdot 09\end{array}$ & $\begin{array}{l}37 \\
36\end{array}$ & $\begin{array}{l}22 \cdot 50 \\
18 \cdot 80\end{array}$ \\
\hline I962 $\left\{\begin{array}{l}\text { Block I } \\
\text { Block II }\end{array}\right.$ & $\begin{array}{l}18 \\
19\end{array}$ & $\begin{array}{r}9.45 \\
24.17\end{array}$ & $\begin{array}{l}19 \\
18\end{array}$ & $\begin{array}{l}13 \cdot 84 \\
26 \cdot 82\end{array}$ & $\begin{array}{l}39 \\
39\end{array}$ & $\begin{array}{l}11 \cdot 18 \\
34 \cdot 56\end{array}$ \\
\hline $\begin{array}{c}\text { Heterogeneity }\left\{\begin{array}{l}\text { Within seasons } \\
\chi^{2}\end{array} \text { Between seasons }\right. \\
\text { Betwe }\end{array}$ & $\begin{array}{l}4 \\
2\end{array}$ & $\begin{array}{l}\text { I1 } 63^{*} \\
5.9^{8}\end{array}$ & $\begin{array}{l}4 \\
2\end{array}$ & $\begin{array}{l}9 \cdot 60 \\
9 \cdot 18^{*}\end{array}$ & $\begin{array}{l}4 \\
2\end{array}$ & $\begin{array}{l}20 \cdot 45^{* * *} \\
2 \cdot 12\end{array}$ \\
\hline
\end{tabular}

* $-\mathrm{P}=0.05-0.01 . \quad * * *-\mathrm{P}=<0.001$

these statistics in terms of four components, an environmental component $\left(\mathrm{E}_{1}\right)$ and three genetic components $(\mathrm{D}),(\mathrm{H})$ and $(\mathrm{F})$. Of these the former measures additivity, $(\mathrm{H})$ dominance, whilst the latter is a cross-product term in $d$ and $h$ which is the only component to take sign depending upon whether increasing or decreasing alleles are the 
more frequently dominant. Since the presence of non-allelic interactions has already been established, the estimates of these components will be inflated in value because they will each contain some of the variation properly attributable to interactions. Some caution must therefore be exercised in interpreting the estimates obtained.

TABLE 12

The expectations of the statistics used to calculate the components of variation together with their observed values for flowering time

\begin{tabular}{|c|c|c|c|c|c|c|c|c|c|}
\hline \multirow{2}{*}{ Statistic } & \multirow{2}{*}{ omposition } & \multirow{2}{*}{ Rank } & \multicolumn{3}{|c|}{1960} & \multicolumn{2}{|c|}{ r $96 \mathrm{I}$} & \multicolumn{2}{|c|}{1962} \\
\hline & & & Block I & Block II & Block III & Block I & Block II & Block I & Block II \\
\hline & & $\ldots$ & $27 \cdot 81$ & $30 \cdot 10$ & $37 \cdot 06$ & $9^{1}$ & 02 & $7 \cdot 8 \mathrm{I}$ & $14 \cdot 45$ \\
\hline V1F2 & $\frac{1}{2} \mathrm{D}+\frac{1}{4} \mathrm{H}+\mathrm{E}_{1}$ & 1 & & & $74 \cdot 79$ & & & & \\
\hline$V_{B 1}$ & $\begin{array}{c}\frac{1}{4} \mathrm{D}-\frac{1}{2} \mathrm{~F}+\frac{1}{4} \mathrm{H} \\
+\mathrm{E}_{1}\end{array}$ & I & $59^{\cdot 62}$ & $4^{1} \cdot 04$ & & $59 \cdot 12$ & $9^{\circ} 05$ & & 29.89 \\
\hline $\mathrm{V}_{\mathrm{B} 2}$ & $\begin{array}{c}\frac{1}{4} \mathrm{D}+\frac{1}{2} \mathrm{~F}+\frac{1}{4} \mathrm{H} \\
+\mathrm{E}_{1}\end{array}$ & I & $46 \cdot 28$ & $53 \cdot 7^{8}$ & $3^{8 \cdot} \cdot 5^{8}$ & $39 \cdot 52$ & $13 \cdot 07$ & $29 \cdot 53$ & $42 \cdot 4^{8}$ \\
\hline$\nabla_{\text {B11 }}$ & $\frac{1}{8} \mathrm{D}-\frac{1}{4} \mathrm{~F}+\frac{1}{8} \mathrm{H}$ & 2 & $65 \cdot 24$ & $45 \cdot 69$ & $44 \cdot 5^{6}$ & $5^{1 \cdot 08}$ & $10 \cdot 91$ & $28 \cdot 04$ & $28 \cdot 31$ \\
\hline$\nabla_{\mathrm{B} 12}$ & $\frac{1}{8} \mathrm{D}+\frac{1}{\mathrm{~F}} \mathrm{~F}+\frac{1}{8} \mathrm{H}$ & 2 & $69 \cdot 95$ & $39 \cdot 82$ & $54 \cdot 01$ & $38 \cdot 85$ & $11 \cdot 51$ & $26 \cdot 24$ & $28 \cdot 49$ \\
\hline$\nabla_{B 1 S}$ & $1 \mathrm{D}+\frac{1}{8} \mathrm{H}+\mathrm{E}_{1}$ & 2 & $56 \cdot 44$ & 55 & 37 & $52 \cdot 16$ & $20 \cdot 5^{8}$ & $31 \cdot 01$ & \\
\hline$\nabla_{\mathrm{B} 21}$ & $\frac{2}{8} \mathrm{D}-\mathrm{H}+\frac{1}{8} \mathrm{H}$ & 2 & $3^{\circ}$ & & 37 & 49.42 & 8.07 & $23 \cdot 10$ & $23 \cdot 35$ \\
\hline$\nabla_{\mathrm{B} 22}$ & $\frac{1}{8} \mathrm{D}+\frac{1}{4} \mathrm{~F}+\frac{1}{8} \mathrm{H}$ & 2 & $5^{1} \cdot 62$ & $43 \cdot 96$ & $42 \cdot 3^{x}$ & $4^{6 \cdot 67}$ & $9 \cdot 3^{6}$ & $12 \cdot 3^{8}$ & $27 \cdot 20$ \\
\hline$\nabla_{\text {B2S }}$ & $1 \mathrm{D}^{+\mathrm{L}_{1}}+\frac{1}{8} \mathrm{H}+\mathrm{E}_{1}$ & 2 & $68 \cdot 31$ & $55^{\prime 2}$ & $77 \cdot 82$ & $56 \cdot 45$ & $15 \cdot 21$ & $3^{6 \cdot 82}$ & 56.03 \\
\hline$V_{\overline{B 11}}$ & $\begin{array}{c}\frac{1}{16} \mathrm{D}-\frac{12}{8} \mathrm{~F}+\frac{1}{16} \mathrm{H} \\
+\operatorname{l} / n\left(\nabla_{\mathrm{B} 11}\right)\end{array}$ & I & $12 \cdot 39$ & $\mathrm{II}^{2}$ & $12 \cdot 03$ & I $8 \cdot 56$ & $10 \cdot 26$ & $7 \cdot 71$ & $7 \cdot 74$ \\
\hline$V_{\overline{\mathrm{B} 12}}$ & $\begin{array}{c}\frac{1}{18} \mathrm{D}+\frac{1}{8} \mathrm{~F}+\frac{1}{18} \mathrm{H} \\
+\mathrm{I} / n(\nabla \mathrm{B} 12)\end{array}$ & I & $24 \cdot 8 I$ & $10 \cdot 67$ & $15 \cdot 82$ & $15 \cdot 06$ & $4 \cdot 23$ & $9 \cdot 3^{6}$ & $6 \cdot 72$ \\
\hline $\mathrm{V} \overline{\mathrm{B1S}}$ & $\begin{array}{r}1 \mathrm{D}-1 \mathrm{~F}+\frac{-1}{16} \mathrm{H} \\
+1 / n(\nabla \mathrm{B} 1 \mathrm{~s})\end{array}$ & 1 & $19 \cdot 27$ & $14 \cdot 4^{8}$ & $23 \cdot 64$ & $54 \cdot 65$ & $14 \cdot 97$ & $7 \cdot 47$ & $9 \cdot 56$ \\
\hline$W \overline{\mathrm{B11}}$ & $\frac{1}{16} \mathrm{D}-\frac{1}{16} \mathrm{H}$ & I & $5 \cdot 61$ & & & 96 & $2 \cdot 98$ & $-3 \cdot 11$ & -0.72 \\
\hline & $\frac{1}{8} \mathrm{D}-\frac{3}{18}$ & I & & & & & & $2 \cdot 12$ & $2 \cdot 14$ \\
\hline WB12 & $\frac{1}{8} \mathrm{D}+\frac{7}{16}$ & 1 & & 2. & & & & $0 \cdot 31$ & -0.59 \\
\hline$V_{\mathrm{B} 21}$ & $\begin{array}{c}\frac{1}{16} \mathrm{D}-\frac{1}{8} \mathrm{~F}+\frac{1}{16} \mathrm{H} \\
+\mathrm{I} / n\left(\nabla_{\mathrm{B} 21}\right)\end{array}$ & I & $23 \cdot 22$ & $8 \cdot 09$ & $7 \cdot 67$ & $19 \cdot 54$ & $3 \cdot 37$ & $6 \cdot 25$ & $9 \cdot 69$ \\
\hline$V_{\overline{B 22}}$ & $\begin{array}{c}\frac{1}{16} \mathrm{D}+\frac{1}{8} \mathrm{~F}+\frac{1}{16} \mathrm{H} \\
+1 / n\left(\nabla_{\mathrm{B} 22}\right)\end{array}$ & I & $28 \cdot 17$ & $23 \cdot 12$ & 13.99 & $24 \cdot 65$ & $3 \cdot 45$ & $4 \cdot 69$ & $6 \cdot 33$ \\
\hline$\sqrt{\mathrm{B} 2 \mathrm{~S}}$ & $\frac{1 \mathrm{D}}{4}+\mathrm{F}+\frac{1}{1 \mathrm{~B}} \mathrm{H}$ & I & $28 \cdot 25$ & $27 \cdot 12$ & $32 \cdot 77$ & $30 \cdot 55$ & $7 \cdot 80$ & $6 \cdot 72$ & $9 \cdot 5^{\circ}$ \\
\hline$W \overline{B 2}$ & $\mathrm{D}_{1}^{\frac{1}{18}}-$ & I & $18 \cdot$ & $10^{\circ}$ & , & $I I \cdot 20$ & $0 \cdot \varepsilon_{0}$ & $2 \cdot 5^{8}$ & $2 \cdot 3^{I}$ \\
\hline$W_{B 21}$ & $\frac{1}{8} \mathrm{D}-\frac{1}{16} \mathrm{~F}-\frac{1}{16} \mathrm{H}$ & I & & II & $10 \cdot 49$ & 13.95 & I. 89 & $2 \cdot 07$ & $4 \cdot 8_{4}$ \\
\hline$W \overline{\mathrm{B} 22 / \mathrm{B} 2 \mathrm{~S}}$ & $\frac{1}{8} \mathrm{D}+\frac{3}{16} \mathrm{~F}+\frac{-1}{16} \mathrm{H}$ & I & 18.86 & $16 \cdot 93$ & $17 \cdot 49$ & $9 \cdot 95$ & $2 \cdot 52$ & $2 \cdot 46$ & $4 \cdot 24$ \\
\hline
\end{tabular}

$n=$ number of individuals within a family of that particular generation.

Unweighted estimates of the components of variance were computed by the least squares technique described by Mather (1949), after appropriate adjustments had been made for genetic sampling errors, from the observed values given in tables 12 and 13 . The genetic picture which emerges from these estimations is predominantly one of additivity for both characters with little evidence from the components 
themselves for either dominance or one type of allele being more frequently dominant than the other (table 14). Furthermore, these estimates confirm that the suggestion of heterosis for height must stem from non-allelic interactions rather than over-dominance, since nowhere does $\mathrm{H}$ quite reach significance at the 5 per cent. level of probability. Thus the ratio $\sqrt{\mathrm{H} / \mathrm{D}}$ which measures apparent dominance can never be significantly greater than $I$ here.

To obtain a more comprehensive picture of how flowering time and height are inherited it is necessary to take linkage effects into account.

TABLE $: 3$

Observed values of the statistics used for calculating the components of variation of height

\begin{tabular}{|c|c|c|c|c|c|c|c|}
\hline \multirow{2}{*}{ Statistic } & \multicolumn{3}{|c|}{1960} & \multicolumn{2}{|c|}{861} & \multicolumn{2}{|c|}{1962} \\
\hline & Block I & Block II & Block III & Block I & Block II & Block I & Block II \\
\hline$E_{1}$ & $45 \cdot 18$ & $25 \cdot 74$ & $19 \cdot 25$ & $25 \cdot 56$ & $14 \cdot 65$ & $I I \cdot 43$ & $24 \cdot 02$ \\
\hline$V_{1 F 2}$ & $52 \cdot 89$ & $28 \cdot 19$ & $60 \cdot 55$ & $56 \cdot 86$ & 35.66 & $3^{n} \cdot 16$ & $47 \cdot 59$ \\
\hline$V_{B 1}$ & $64 \cdot 77$ & $38 \cdot 04$ & $22 \cdot 04$ & $3^{6 \cdot 25}$ & $25 \cdot 8 \mathrm{r}$ & $8 \cdot 19$ & 29.55 \\
\hline $\mathrm{VB}_{\mathrm{B}}$ & $66 \cdot 04$ & $4^{\mathrm{r} \cdot 66}$ & $44 \cdot 75$ & $34 \cdot 12$ & $29 \cdot 3 !$ & $23 \cdot 69$ & 34.40 \\
\hline$\nabla_{B 11}$ & $40 \cdot 27$ & $23 \cdot 9^{1}$ & $22 \cdot 78$ & $25 \cdot 4^{\circ}$ & 19.08 & II.79 & $22 \cdot 84$ \\
\hline$\nabla_{\mathrm{B} 12}$ & $56 \cdot 03$ & 35.90 & $4^{\mathrm{r} \cdot 02}$ & $35 \cdot 24$ & $20 \cdot 88$ & 14.09 & $22 \cdot 15$ \\
\hline$\nabla_{\text {B1S }}$ & $58 \cdot 5^{\circ}$ & 25.08 & $28 \cdot 99$ & $32 \cdot 93$ & 23.75 & 18.93 & $33 \cdot 73$ \\
\hline$\nabla_{\text {B21 }}$ & $39 \cdot 63$ & $29 \cdot 72$ & 26.80 & $32 \cdot 28$ & 17.48 & $20 \cdot 06$ & $22 \cdot 67$ \\
\hline$\nabla_{\text {B22 }}$ & $60 \cdot 07$ & $35 \cdot 7^{1}$ & $35 \cdot 19$ & $35 \cdot 29$ & $16 \cdot 55$ & 19.54 & $37 \cdot 45$ \\
\hline$\nabla_{\text {B2S }}$ & 84.43 & $28 \cdot 42$ & $39 \cdot 56$ & $45 \cdot 69$ & $23 \cdot 5 !$ & $22 \cdot 22$ & $26 \cdot 62$ \\
\hline VB11 & $8 \cdot 7^{2}$ & $4 \cdot 43$ & $5 \cdot 06$ & 12.01 & $12 \cdot 08$ & $5 \cdot 9^{8}$ & $4 \cdot 75$ \\
\hline VB12 & $4 \cdot 59$ & $9 \cdot 37$ & 3.97 & $17 \cdot 08$ & $7 \cdot 29$ & $8 \cdot 23$ & 15.11 \\
\hline$V_{\mathrm{B} 1 \mathrm{~S}}$ & $24 \cdot 5^{1}$ & ro.79 & $12 \cdot 96$ & $24 \cdot 36$ & 13.96 & $7 \cdot 48$ & $5 \cdot 73$ \\
\hline$W \overline{\mathrm{B11/ \textrm {B } 1 2}}$ & $1 \cdot 36$ & $2 \cdot 09$ & '.95 & $5 \cdot 37$ & $4 \cdot 76$ & 0.15 & 3.36 \\
\hline $\mathrm{W}_{\mathrm{B} 11 / \mathrm{B} 1 \mathrm{~S}}$ & $8 \cdot 02$ & $4 \cdot 88$ & $5 \cdot 36$ & $12 \cdot 77$ & $8 \cdot 14$ & $4 \cdot 98$ & 3.55 \\
\hline WB12/B1S & $-0 \cdot 39$ & $3 \cdot 5^{8}$ & $-1 \cdot 29$ & 10.94 & $4 \cdot 3^{1}$ & 2.06 & $4 \cdot 62$ \\
\hline VB21 & $8 \cdot 90$ & $7 \cdot 92$ & $8 \cdot 7 \mathrm{I}$ & 12.55 & $7 \cdot 66$ & $7 \cdot 68$ & $9 \cdot 16$ \\
\hline V & $21 \cdot 5 r$ & $3^{0} \cdot 6 x$ & $32 \cdot 06$ & $20 \cdot 87$ & $7 \cdot 42$ & $3 \cdot 25$ & 15.65 \\
\hline VB2S & 17.90 & $9 \cdot 20$ & $28 \cdot 46$ & $26 \cdot 95$ & ro.25 & 4.58 & 9.65 \\
\hline$W \overline{\mathrm{B} 21 / \mathrm{B} 22}$ & $-2 \cdot 43$ & $-1 \cdot 79$ & -5.43 & $6 \cdot 22$ & 3.01 & $1 \cdot 72$ & $7 \cdot 34$ \\
\hline$W \mathrm{B21/ \textrm {B } 2 \mathrm { S }}$ & $5 \cdot 63$ & 3.63 & 4.75 & 18.06 & $4 \cdot 52$ & $3 \cdot 10$ & $6 \cdot 65$ \\
\hline WB22/B2S & -0.58 & $0 \cdot 49$ & $9 \cdot 44$ & $12 \cdot 96$ & $4 \cdot 85$ & $1 \cdot 90$ & $6 \cdot 33$ \\
\hline
\end{tabular}

This can be achieved by redefining the components so as to relate them to the number of cycles of recombination undergone by the plants or families comprising a particular statistic (i.e. ranking-see table I2). Definitions of the exclusive components required to take full account of linkage in this experiment are given in table 15 and their calculated values in table 16 . By successive fitting of inclusive and exclusive models to the data and analysis of the resultant squared deviations between the observed and expected values of the statistics it becomes possible to determine whether a significant amount of the variation present can be attributed to linkage. The deviation S.S. obtained from fitting the inclusive model will include variation due to three sources; linkage, residual interaction and error, whereas the exclusive 

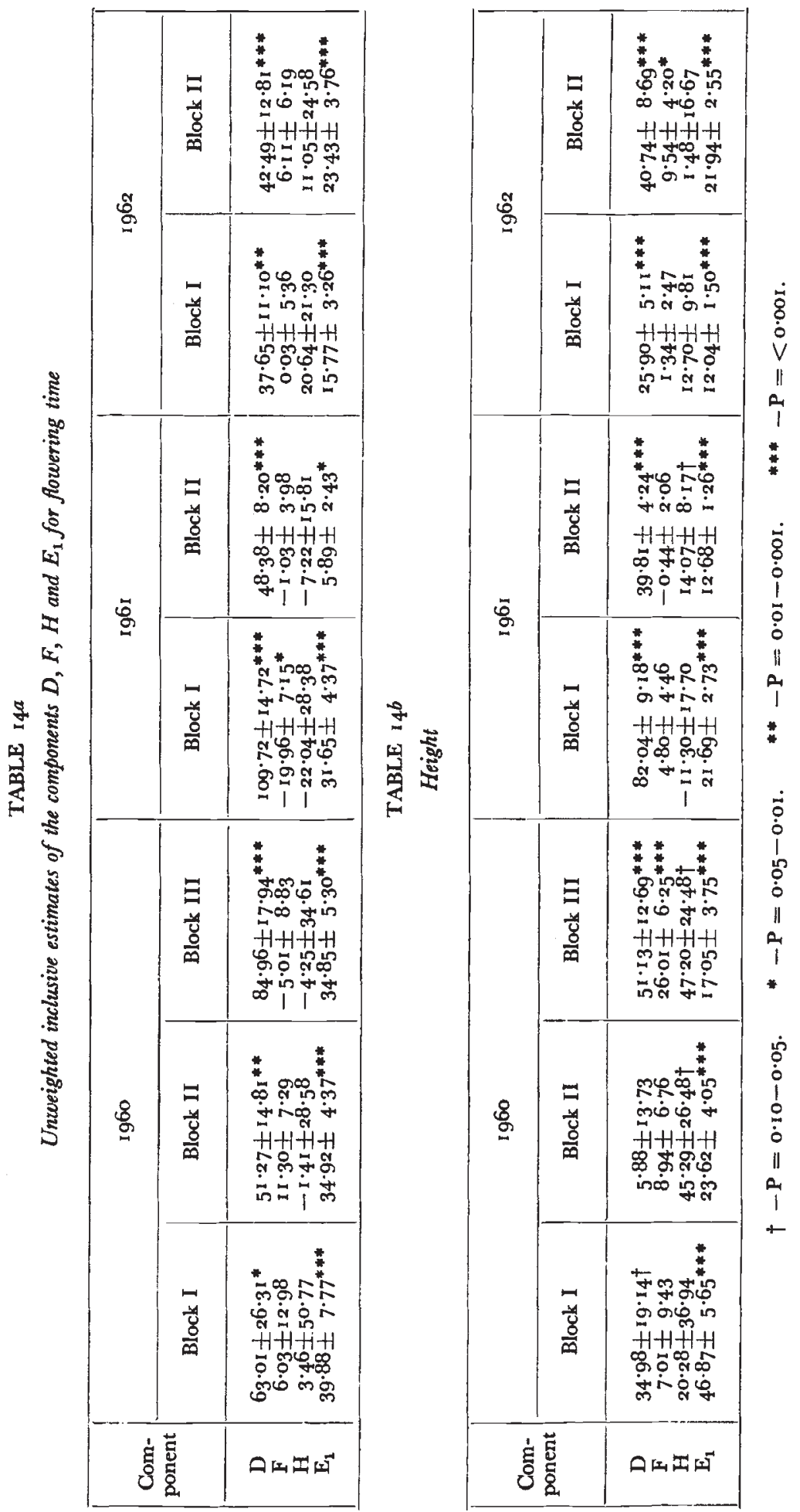


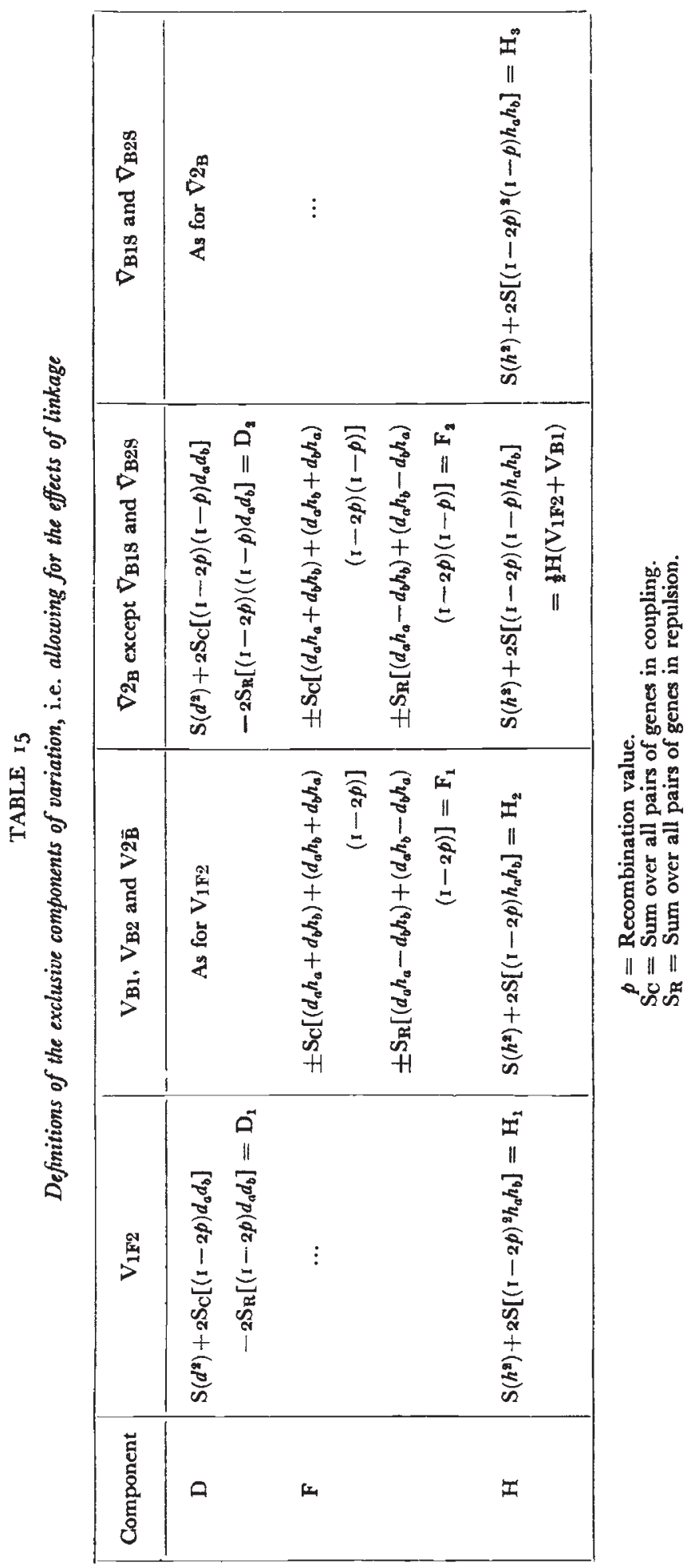


S.S. can contain only variation from the last two sources. Both this analysis in which seasons are considered separately and that in which seasons are analysed jointly in order to test consistency over blocks and seasons have been described in detail by Mather (1949) and by Mather and Vines (1952) so only an outline of the analysis will be presented here. There are 22 basic equations and hence 22 degrees of freedom for differences between observed and expected of which 4 are used in fitting initially the inclusive components $D, F, H$ and $E_{1}$. The exclusive analysis involves a further 4 components leaving $14 \mathrm{~d}$.f. for the measurement of residual interactions. Because the blocks of the $196 \mathrm{r}$ and 1962 experiments were separated in time it was decided to allow for differences between them in the analysis. This slight modification means that the estimate of error variation consists solely of the blocks $x$ statistics interaction which it must always do if there are significant differences between blocks.

The season by season analyses given in table $\mathrm{I} 7$ provide no evidence either of linkage or residual disturbance for height. This agrees reasonably well with the results of the scaling tests carried out earlier. But for flowering time there is good evidence for linkage in two of the seasons- 1960 and 1962 -where this item is significant or bordering on significance even when tested against the residual interaction mean square. Yet in $19^{6} \mathrm{I}$ there is not the slightest trace of linkage. Furthermore previous analyses suggest that non-allelic interactions constitute a major source of variation in this character but the item measuring residual disturbances is nowhere significant. The answer to this apparent contradiction lies partly in the fact that the linkage item itself can contain some of the variation due to interactions and partly in the experimental design. The spatial separation of individual plants within families both in the glasshouse and the field; the different sowing dates of the blocks in the two seasons; the environmental instability of the character are all factors which will contribute to and hence tend to increase the estimate of error and thereby decrease the sensitivity of the test of significance. These factors will of course affect height also but to a lesser extent.

Turning to the joint anaiysis of seasons, as expected there is no reason to believe that linkage is affecting the genes controlling height (table 18). There is, however, evidence for residual disturbances since the main item is significantly larger than the residual interaction $x$ year item. For flowering time, on the other hand, there is evidence for an overall linkage effect. Analysis reveals $D$ to be the most important of the linkage components since out of a total linkage S.S. of 960 it alone accounts for just over 800 . This indicates that in the inbred lines coupling and repulsion linkages do not balance, but rather there is a marked excess of one linkage phase over the other. However, this point will be raised again later. It is also evident from these analyses that linkage is not entirely consistent over seasons due presumably to the $196 \mathrm{I}$ results. The calculated values of the exclusive 


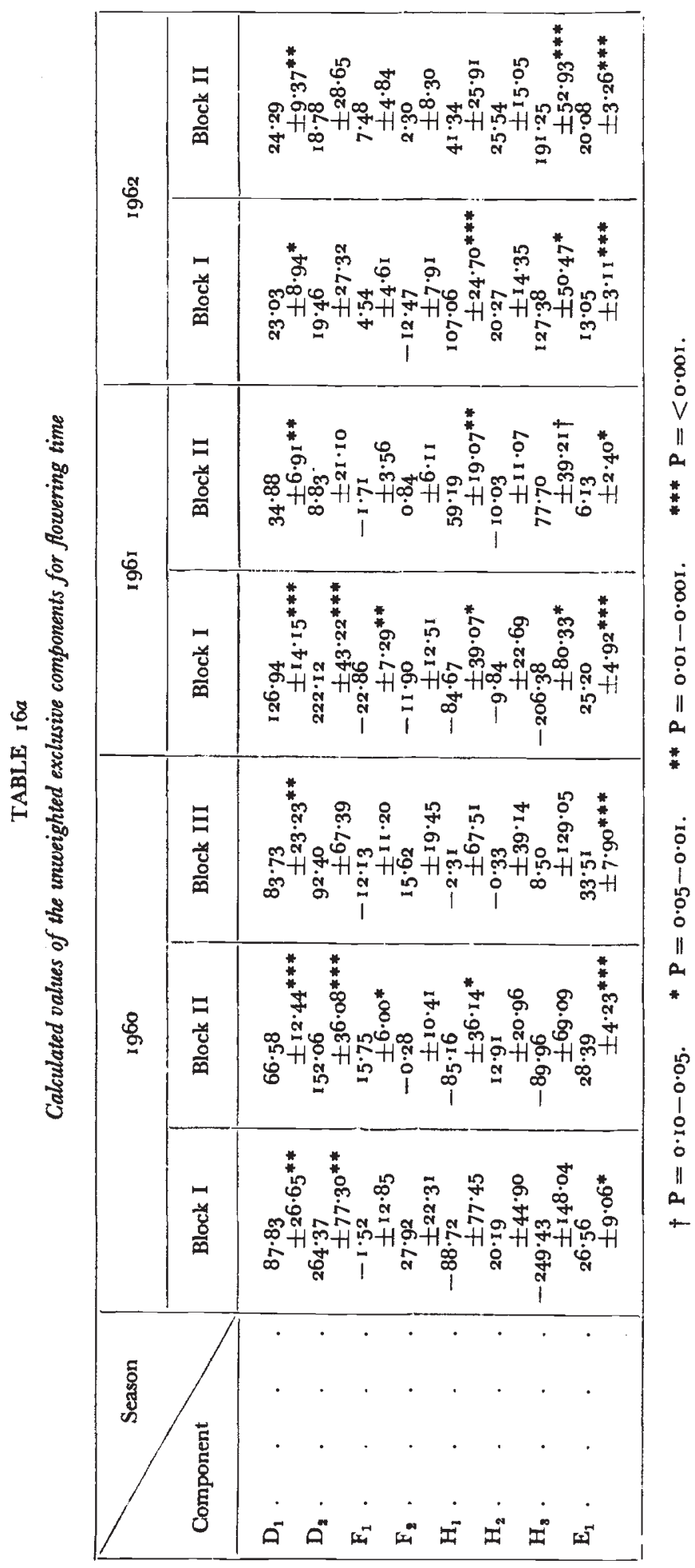




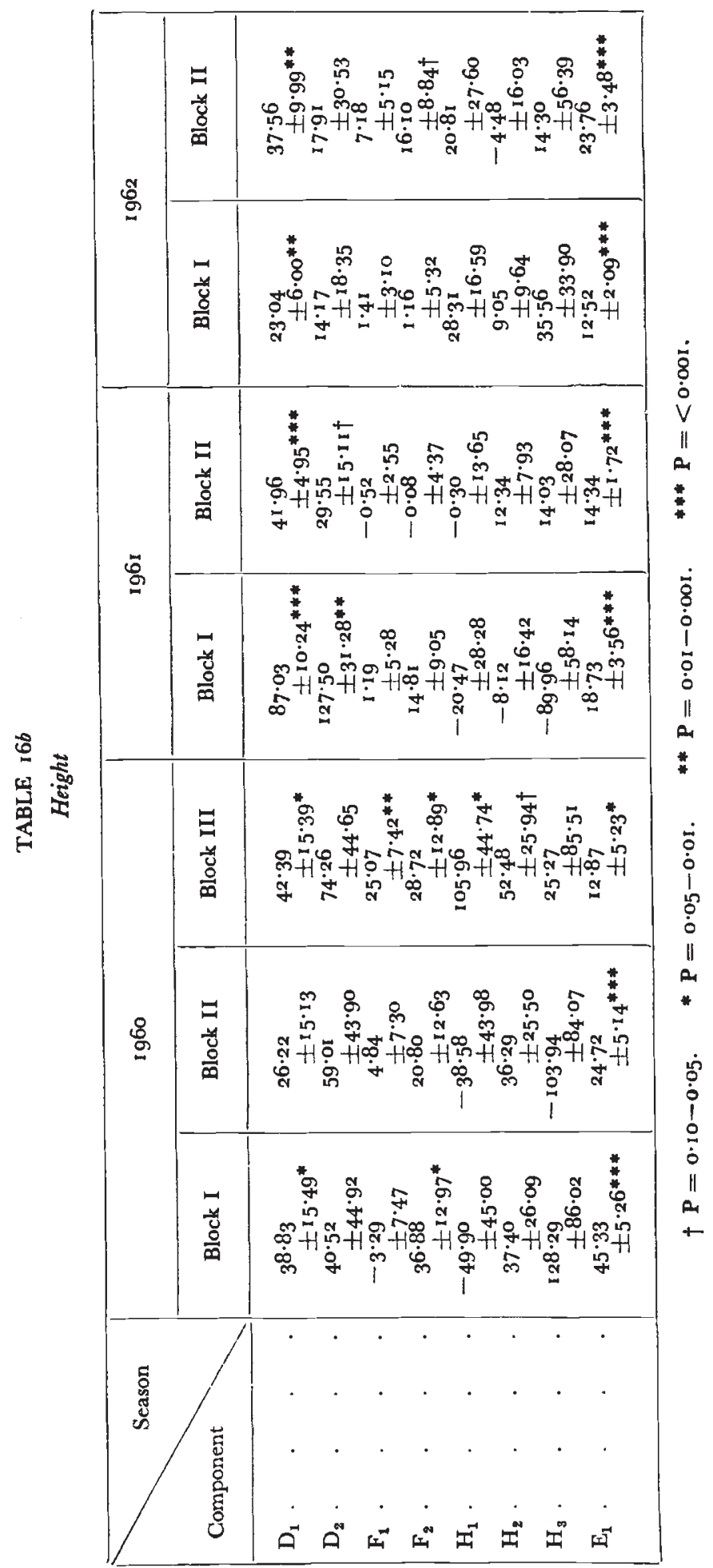




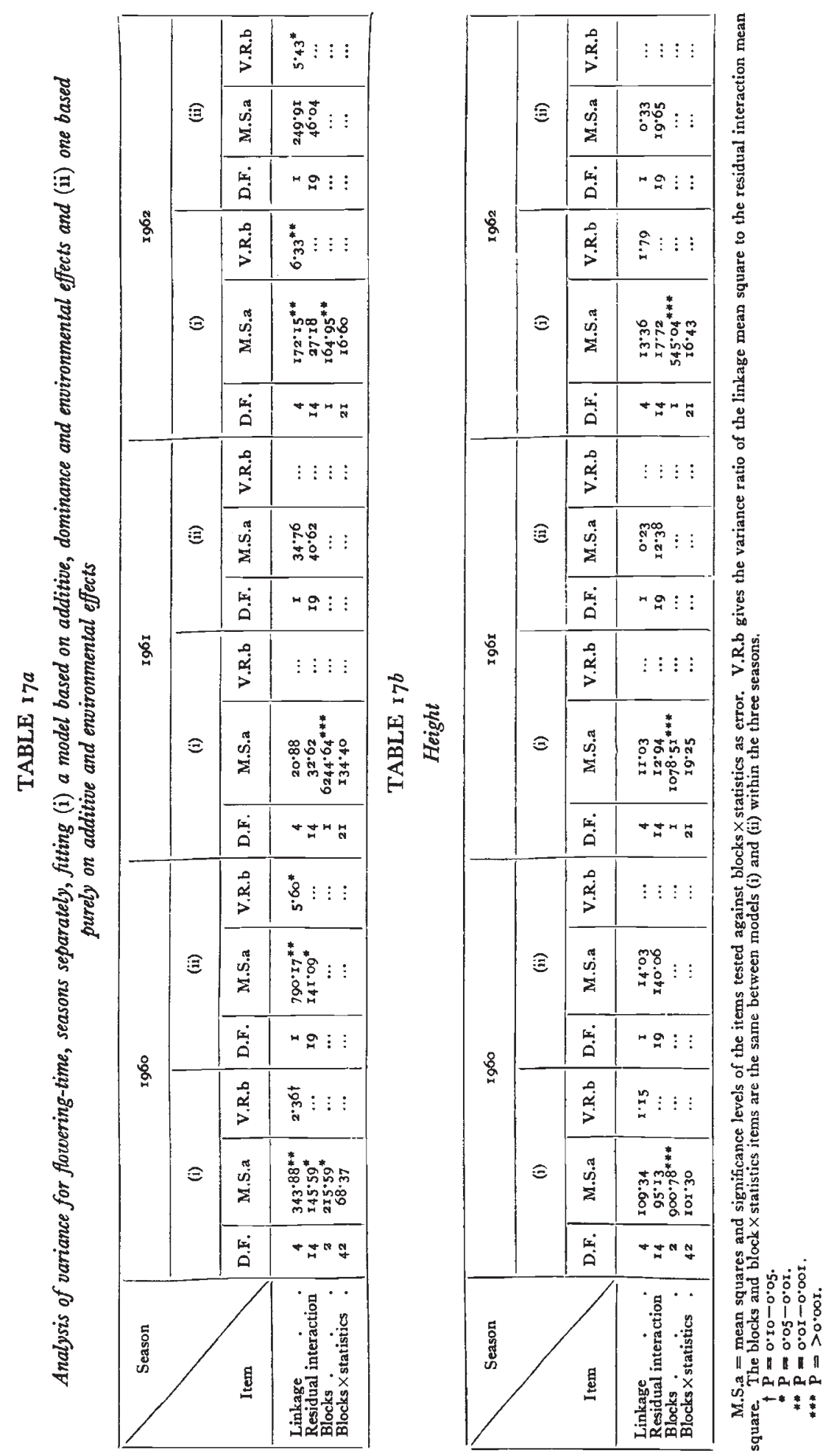


components likewise reflect this inconsistency. Thus the $\mathrm{H}$ components range from being significantly negative in 1960 and $196 \mathrm{I}$ (Block $I$ ) to being significantly positive in I96I (Block II) and I962 (see table I6). Negative values for these components are meaningless and are probably the direct result of the interactions known to exist. Whilst the heterogeneity of the components is greater between than within seasons for both characters this difference does not prove to be significant. Mather and Vines ( 1952 ) and Jinks ( 1956 ), however, both found that, whereas for height the components were equally stable within and between

TABLE 18

Analysis of variation for flowering time and height-seasons jointly. Model (i) includes dominance effects, model (ii) is a purely additive model

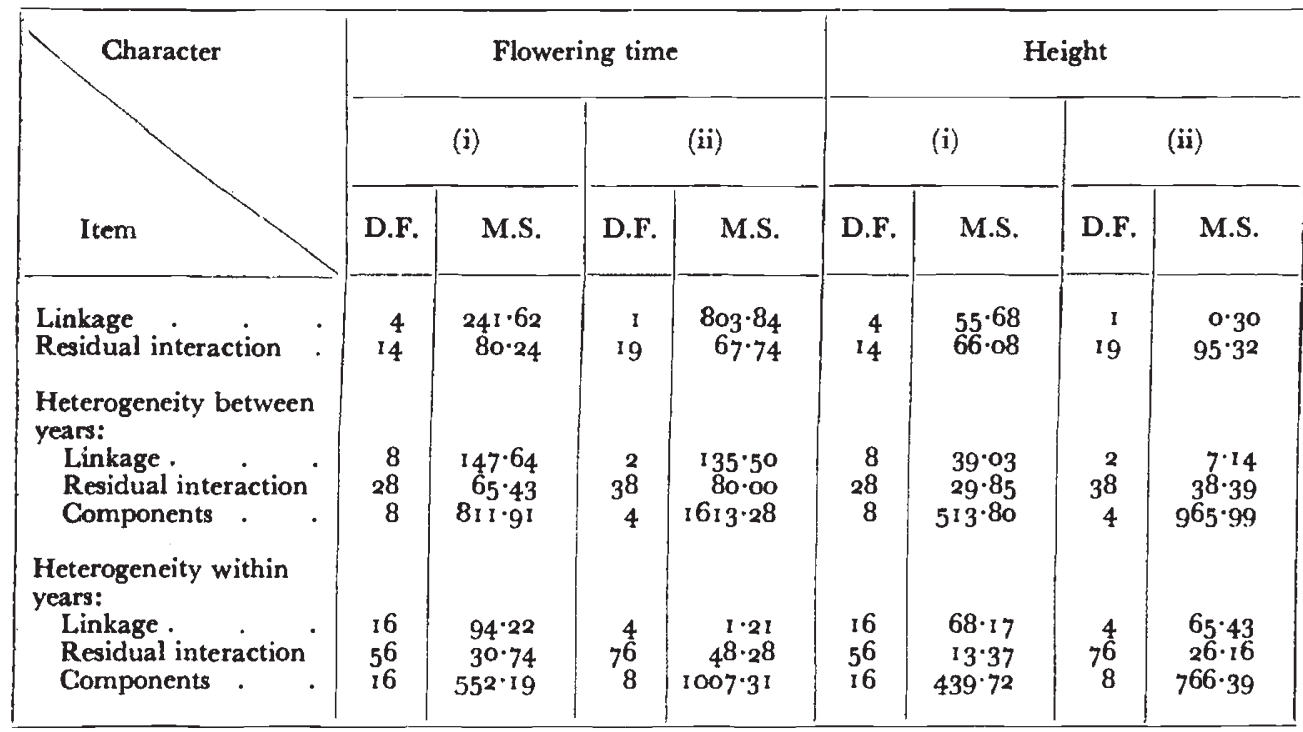

seasons, for flowering time the components were considerably more variable between seasons. The comparison of these results with either of the previous experiments is not strictly valid for reasons which have already been disclosed.

After fitting inclusive and exclusive models to the data based on additive, dominance and environmental effects, models were then fitted which depended solely on additive and environmental effects. It is of interest to combine the resultant analyses of the two models as they may shed further light on the inheritance of the characters under investigation. Basically this enables the inclusive and exclusive $\mathrm{H}$ and $\mathrm{F}$ components to be examined more fully. There can be little doubt that these two components play only an insignificant role in the expression of flowering time, the major genetic component being additive (see table 19). For height, however, the situation is rather different, since the item measuring overall dominance is approaching significance at 
the I per cent. level of probability when tested against the main residual interaction item. Dominance cannot therefore be ignored here, it is not just a reflection of the non-allelic interactions which are known to be present.

In conclusion, the pattern of inheritance emerging from these unweighted analyses differs markedly between the two characters. Flowering time is controlled by genes which are mainly additive in effect and are probably linked whereas height is governed by unlinked genes which exhibit dominance.

\section{(iii) Weighted estimation of the components of variation}

Hitherto we have considered only the unweighted least squares estimates of the components which, though easy to perform, suffer

TABLE 19

Analysis of variation for flowering time and final height-combining models (i) and (ii)

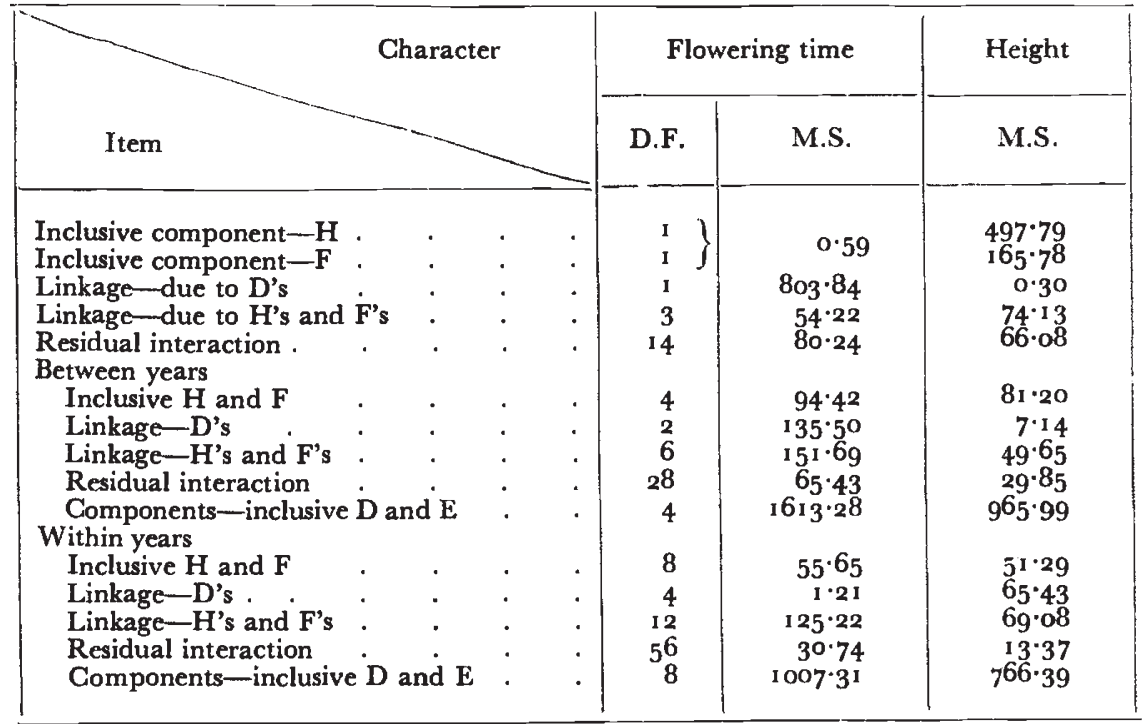

from the drawback that they take account neither of the correlations which must exist between some of the calculated values of the statistics, nor of the differing precisions with which they are observed experimentally. Adopting a weighted procedure which can take account of both these factors should enable more efficient estimates of the components to be obtained.

A weighted least squares analysis designed to meet these requirements has been programmed for the Elliott $40 \mathrm{I}$ computer at Rothamsted, full details of which have been given by Cooke et al. (1962). Before the estimation could proceed, however, the data had to be tailored to fit the capacity of the computer. This entailed firstly a reduction in the number of statistics from 22 to 16 ; secondly, that the 

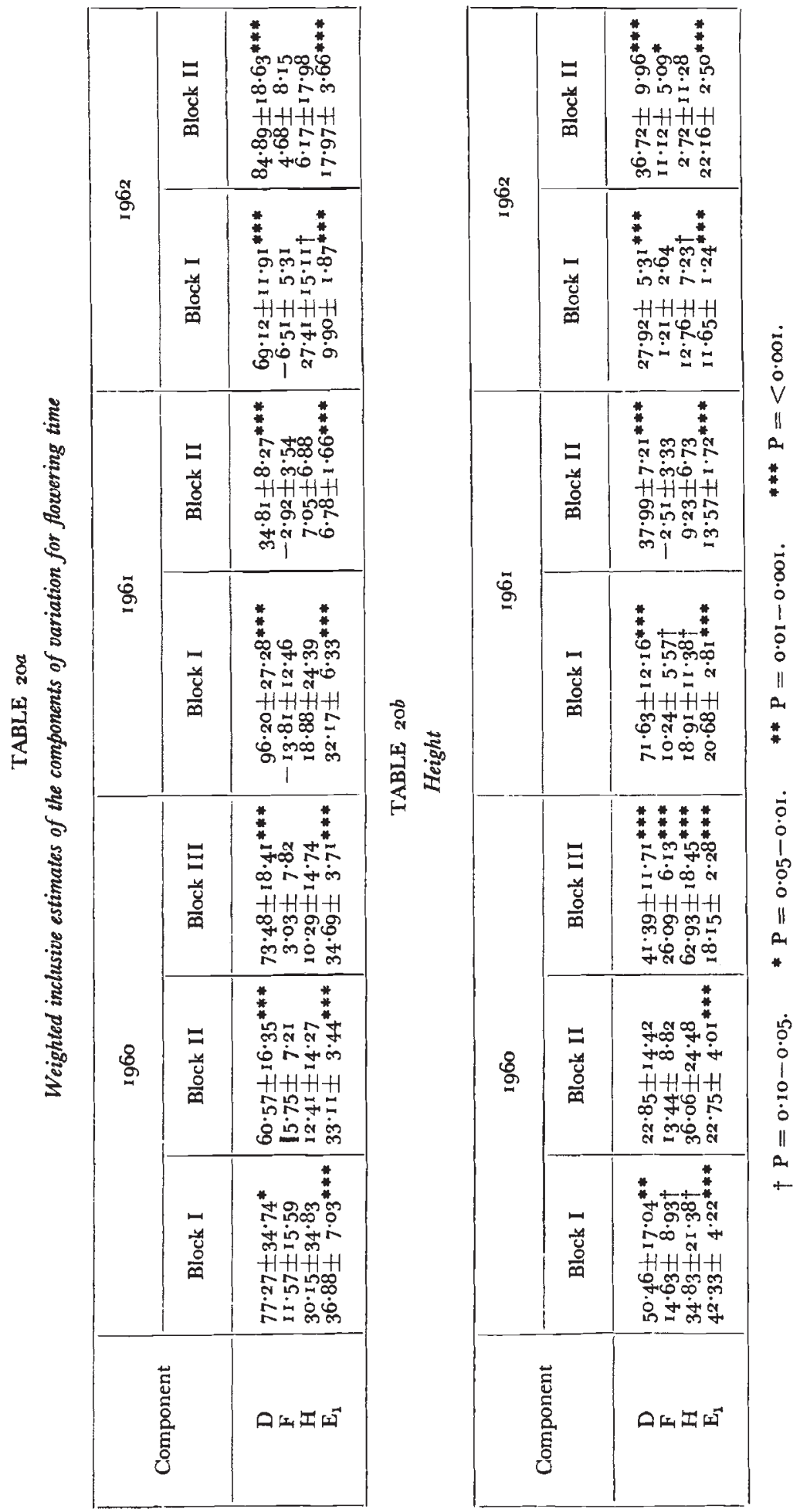


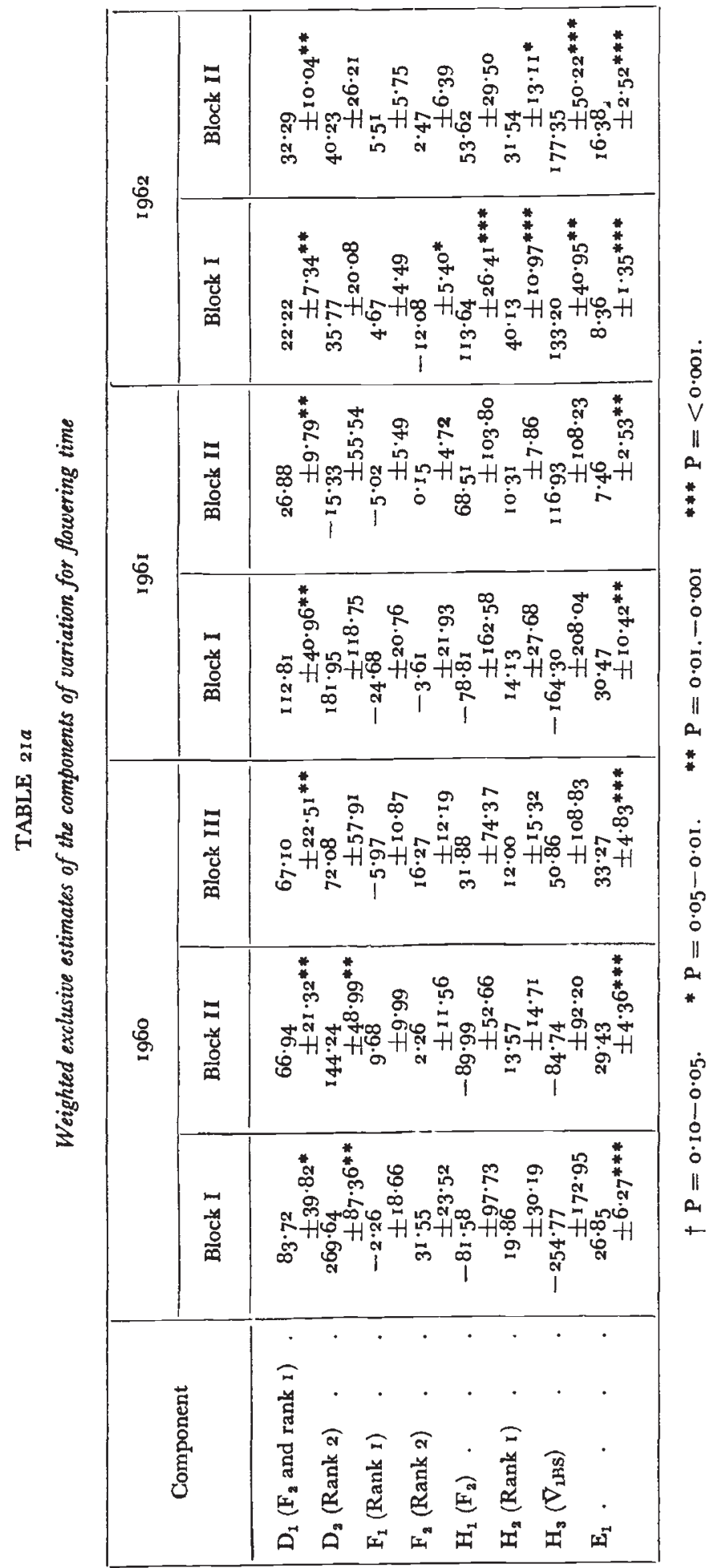




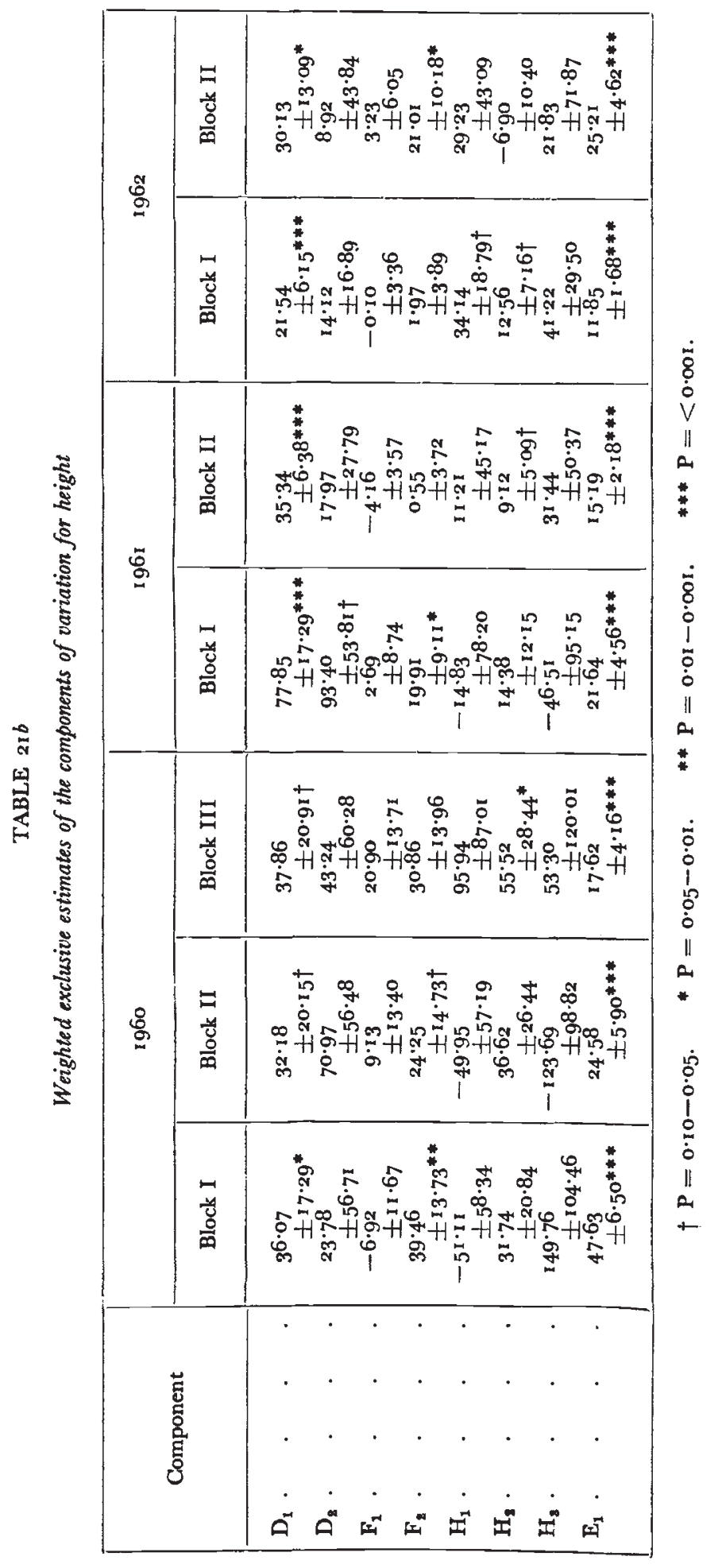


maximum number of components to be estimated should not exceed 8 . The requisite cut in the number of statistics was achieved by calculating pooled estimates for those statistics having identical expectations. Inspection of table 12 shows that $\mathrm{V}_{\overline{\mathrm{B} 11}}$ and $\mathrm{V}_{\overline{\mathrm{B} 21}} ; \mathrm{V}_{\overline{\mathrm{B} 12}}$ and $\mathrm{V}_{\overline{\mathrm{B} 22}}$ and $\mathrm{W}_{\overline{\mathrm{B} 11 / \mathrm{B} 12}}$ and $\mathrm{W}_{\overline{\mathrm{B} 21 / \mathrm{B} 22}}$ can be combined in this way. Likewise all the information yielded by the rank 2 variances can be condensed into three statistics. As regards the components, the inclusive estimates present no problems since there are invariably only four to be estimated, whilst in the exclusive analyses this difficulty can be overcome by putting the $\overline{\mathrm{V} 2}{ }_{\mathrm{B}} \mathrm{H}$ component equal to $\frac{1}{2}\left(\mathrm{~V}_{1 \mathrm{~F} 2}+\mathrm{V}_{\mathrm{B} 1}\right)$ as in the unweighted estimations (see table I5). A sampling variance matrix which incorporated all these features has been devised by my colleague Mr R. Morley Jones. This matrix formed the basis for all the weighted analyses, though certain minor modifications had to be made to the expectations of the statistics in order to accommodate seasonal differences in the genetic sampling terms arising from structural alterations in the experimental design. None of the information contained in the data has been sacrificed during the formation of this matrix by combining certain of the statistics or by eliminating one of the components, but these manipulations do mean that the $\chi^{2}$ testing the goodness of fit of the model to the data is now based on correspondingly fewer degrees of freedom.

Substantially the same genetic picture emerges from the weighted inclusive and exclusive analyses as was obtained from the corresponding unweighted analyses. Again, however, the interpretation of the results is beset with difficulties since the models are fitted on the assumption of no non-allelic interactions. That several of the models do not fit the data adequately is a clear demonstration that such interactions exist. Consequently to obtain valid estimates of the standard errors of the components in those particular models the elements of the inverted sampling variance matrix have to be scaled up by a factor based on the observed $\chi^{2}$ divided by its expected value, i.e. the degrees of freedom. Having done this, it is obvious that the major genetic component for both characters is additive (Table 20). Equally it is apparent that for height, dominance cannot be entirely disregarded as the $\mathrm{H}$ component is either significant or verging on significance on several occasions, a result which is in complete agreement with that obtained from the unweighted analyses.

Turning to the exclusive analyses, again there is no suggestion that the genes controlling height are linked. But for flowering time there is evidence both from the component values given in table $2 \mathrm{I}$, and from the tests of goodness of fit of particular models (table 22) that the genes concerned are linked. For any one block, the difference between the $\chi^{2}$ values of the inclusive and exclusive models provides a measure of linkage, whilst the $\chi^{2}$ remaining after having fitted the exclusive model estimates the disturbance due to residual interactions. Dividing by the appropriate degrees of freedom converts the $\chi^{2}$ values into mean 
squares whence it becomes possible from a variance ratio test to determine whether the linkage effect is genuine or merely a reflection of residual interactions. Such a test is only valid however if the interactions affect all the components to an equal extent. Since we have no evidence to the contrary it will be assumed that this requirement is fulfilled. On the basis of this test it is clear that the only real evidence for linkage comes from the 1962 experiment. But since it has already been established that the principal effect of linkage is on the $\mathrm{D}$ component, significant differences between the rank estimates of this

TABLE $22 a$

The detection of linkage in the weighted analyses-flowering time-degrees of freedom and mean squares. Linkage has been tested against residual interactions and this latter item has been tested against experimental error

\begin{tabular}{|c|c|c|c|c|c|c|c|c|}
\hline \multirow{2}{*}{ Item } & \multirow{2}{*}{ D.F. } & \multicolumn{3}{|c|}{ I96o } & \multicolumn{2}{|c|}{196 I } & \multicolumn{2}{|c|}{1962} \\
\hline & & Block I & Block II & Block III & Block I & Block II & Block I & Block II \\
\hline Linkage . & 4 & $4^{\circ} 17$ & $x \cdot 76$ & 0.27 & $2 \cdot 79$ & $3.3 \mathrm{I}$ & $4 \cdot 24^{* *}$ & $6 \cdot 14^{*}$ \\
\hline Residual interaction & 8 & $2 \cdot 3 r^{*}$ & $\mathrm{I} \cdot 4 \mathrm{I}$ & 0.84 & $5 \cdot 56^{* * *}$ & $4 \cdot 93^{* * *}$ & 0.55 & $I \cdot 13$ \\
\hline
\end{tabular}

TABLE $22 b$

Height

\begin{tabular}{|c|c|c|c|c|c|c|c|c|}
\hline \multirow{2}{*}{ Item } & \multirow{2}{*}{ D.F. } & \multicolumn{3}{|c|}{ I96o } & \multicolumn{2}{|c|}{ Ig6I } & \multicolumn{2}{|c|}{1962} \\
\hline & & Block I & Block II & Block III & Block I & Block II & Block I & Block II \\
\hline Linkage & 4 & $3 \cdot 64^{*}$ & $3 \cdot 38$ & V. small & $r \cdot 39$ & $2 \cdot 95$ & 0.09 & 0.77 \\
\hline Residual interaction & 8 & 0.52 & $2 \cdot 65 * *$ & $2 \cdot 34^{*}$ & $2 \cdot 03^{*}$ & $1 \cdot 25$ & $0 \cdot 75$ & $2 \cdot 4^{6 *}$ \\
\hline
\end{tabular}

$$
\text { *P=0.05-0.01. ** P }=0.01-0.001 . \quad \text { *** P }=<0.001 .
$$

component will also indicate to a certain extent the presence of linkage. After allowing for the correlation between the additive components, $D_{2}$ is significantly larger than $D_{1}$ in 1960 , suggesting that the genes are linked in repulsion in the two parental varieties.

Finally concerning the questions of the relative efficiencies of the weighted and unweighted analyses, it proves difficult to make a valid comparison since the method evolved by Nelder ( 1960 ) assumes that interactions are non-existent. Nelder's method can be used, however, providing only those results known to be largely free of such interactions are considered, namely the height data of 1962 . Of the genetic components $\mathrm{H}$ is the least efficiently estimated by the unweighted 
technique, whereas relatively little information about $\mathrm{D}, \mathrm{F}$ and $\mathrm{E}_{\mathbf{1}}$, is sacrificed by this analysis. These results agree with those obtained by Cooke et al. (1962) in an investigation involving inbred lines of Drosophila melanogaster.

\section{CORRELATIONS BETWEEN FLOWERING TIME AND FINAL HEIGHT}

Throughout these analyses the two characters under investigation have been considered separately. It is known, however, that a correlation exists between them in so far as the earlier-flowering plants tend to be the shorter and vice versa. The weighted analyses reveal that there is a correspondence between the total sums of squares for the two characters over blocks and seasons (table 23). This indicates

TABLE 23

Weighted inclusive total sums of squares for flowering time and final height over blocks and seasons

\begin{tabular}{|l|c|c|c|c|c|c|c|}
\hline \multirow{2}{*}{ Character } & \multicolumn{3}{|c|}{1960} & \multicolumn{2}{|c|}{1961} & \multicolumn{2}{c|}{1962} \\
\cline { 2 - 7 } & Block I & Block II & Block III & Block I & Block II & Block I & Block II \\
\hline Flowering time & $\begin{array}{l}489 \cdot 37 \\
\text { Height }\end{array}$ & $\begin{array}{l}471^{\prime} \cdot 77 \\
48 \cdot 3^{8}\end{array}$ & $\begin{array}{l}463 \cdot 25 \\
47 \cdot \cdot 14\end{array}$ & $\begin{array}{l}1126 \cdot 13 \\
1103 \cdot 78\end{array}$ & $\begin{array}{l}1040 \cdot 64 \\
1029 \cdot 63\end{array}$ & $\begin{array}{l}874 \cdot 46 \\
843 \cdot 69\end{array}$ & $\begin{array}{l}839 \cdot 53 \\
840 \cdot 74\end{array}$ \\
\hline
\end{tabular}

that the correlation extends beyond the generation means to include the variances and covariances. Moreover this correlation exists for individual statistics such as $\mathrm{V}_{1} F_{2}, \mathrm{~V}_{\mathrm{B}_{1}}$, etc. This appears to imply that the two characters have genes in common, although differences in the mode of inheritance suggest that some of the genes are at separate though closely linked loci. It would seem, however, that further research is required to elucidate the causes of this correlation.

\section{DISCUSSION}

The inheritance of flowering time and final height in the $1 \times 5$ cross of $\mathcal{N}$. rustica has been extensively studied from different viewpoints by various workers including Mather and Vines (1952), Breese (r954), Jinks and Mather (1955) and Opsahl (1956) and it is therefore of some interest to compare and contrast previous results with those presented here. The first two investigations, which used the $F_{2}$ selfing series of generations, revealed non-allelic interactions in both characters, but were unable to detect dominance for either flowering time or height. Evidence of linkage for flowering time was obtained in both experiments. Jinks and Mather's investigation was concerned primarily with stability in homozygotes and heterozygotes. They found that the 
$F_{1}$ was no more stable than its parents, a conclusion which is completely supported by the present experiment. In an attempt to discriminate between linkage and interactions Opsahl developed a novel approach using $F_{2}$ backcross generations. This increased the precision of his experiment thereby enabling him to show that height was relatively free from interactions and that the genes controlling this character exhibited dominance. From the sequential analyses which he devised he was unable to detect linkage unambiguously for flowering time because of the large residual disturbances.

The results presented here are in general agreement with those from Opsahl's experiment. There are, however, certain features of this experiment, concerned primarily with the first and second degree components, which require explanation. It is perfectly clear from the components of generation means that if all the genes governing flowering time and final height are taken into consideration, then both characters show additive and dominance effects. This is because the models fitted specifically allow for gene interactions and this in turn enables average additive and dominance effects which are free of interactions to be estimated. Why then is it necessary to obtain estimates of the components of variance? The reasons are twofold; firstly to determine the role of linkage in the inheritance of a given character and secondly to calculate the relative magnitudes of additivity and dominance, since the components of the means only estimate the balance of these effects over all genes and as such they cannot, for example, yield an estimate of dominance. When fitting models to the variances and covariances no allowances for interactions are possible because there are never enough statistics available to permit them all to be estimated. Consequently these effects will be incorporated into those components which are being estimated and also into their errors. Discrepancies can therefore arise between the components of means and those of variances. But, since the former can take account of interactions, greater reliability can be placed on the qualitative genetic picture which they give as opposed to the one presented by the components of second degree statistics.

Focusing our attention now on the relative merits of the backcross and $\mathrm{F}_{2}$ selfing series approaches to quantitative inheritance, undoubtedly the extra demands both on time and labour made by the backcrosses must be entered on the debit side of the account. Assuming that the species concerned can be readily selfed it will take at least four times as long to generate the complete set of backcross progenies than it will to obtain the $F_{3}$ generation. There are, however, other factors to be reckoned with in biometrical investigations which should outweigh the purely technical considerations. Basically these factors come under the heading of what might be termed the overall experimental efficiency. This can be subdivided into two parts, general and specific, of which the former is a property of the number of families and individuals raised in a given experiment. Clearly the number of 
plants grown should be sufficient to ensure that statistics based on them are estimated with reasonable precision. The specific portion of the overall efficiency will depend in turn upon the actual generations grown in an experiment; the number of statistics which can be derived from those generations and finally the amount of information which the available statistics can supply about the components being estimated. Judging the two approaches on the basis of these criteria, the backcross technique is unquestionably the more efficient.

In the first place the backcross approach yields considerably more information both about the components of means and of variances. It permits all the first and second order interaction parameters to be estimated if needs be, whereas, excluding the parental generations, the selfing series can only yield information about $[h],[l]$ and $[z]$ irrespective of the model being used to define the parameters. Likewise two generations of backcrossing provide at least 2 I statistics with which to estimate the genetic components of variance, whereas selfing would have to be continued at least until the $F_{6}$ generation before an equivalent number of statistics could be obtained. Moreover the backcross method is, comparatively speaking, an efficient method of estimating $\mathrm{H}$, since none of the available statistics in the current experiment has a coefficient of less than $\frac{1}{16}$ for this component. As one progresses down the selfing series, on the other hand, the coefficient in $\mathrm{H}$ decreases according to the formula $\left(\frac{1}{2}\right)^{r-1}\left(\frac{1}{4}\right)^{n-r}$, where $r=$ rank and $n$ the generation such that $n \geqq r+\mathbf{I} \geqq 2$. A similar, though less rapid, decline would be observed in the $\mathrm{H}$ coefficient if backcrossing were continued beyond the second generation, but as some 20 statistics have already been amassed by this time there is no real need to raise succeeding backcross generations. The other components, being more efficiently estimated, are rather less sensitive than $\mathrm{H}$ to compositional changes in the experiment.

An added advantage which is conferred by the present experimental procedure is that, since all covariance statistics are essentially correlations between half sibs, they will be largely free from any of the more gross effects of genotype $\times$ environment interactions. For this reason parent-offspring correlations, such as $W_{\mathrm{B} 1 / \overline{\mathrm{B11}}}$, which involve plants grown in successive seasons under entirely different environmental conditions, have been deliberately excluded from the list of available statistics. In the $\mathbf{F}_{2}$ selfing series all the covariances are of this latter type. Normally genotype $\times$ environment interactions reduce the parent-offspring correlation, but under very exceptional circumstances it is conceivable that the observed correlation could be higher than its expected value.

On the balance therefore backcrossing would appear to be the better of the two approaches for investigating the inheritance of quantitative characters. Still further improvements would be possible, however, if statistics yielding more information about $\mathrm{H}$ could be devised. Overcoming this obstacle would entail an extensive crossing 
programme involving principally the $\mathrm{F}_{2}$ and I st backcross generations. Plants chosen at random from these generations would have to be selfed and crossed in turn to each parent and the $F_{1}$ generation. This would give a set of I 8 closely interwoven generations providing between them well over 40 statistics, 6 of which would contain coefficients of $\frac{1}{4} \mathrm{H}$. Such a crossing programme may in certain instances make prohibitive demands on both time and labour, but given suitable material this design will furnish detailed information about the components of variation and many other aspects of quantitative inheritance.

\section{SUMMARY}

A biometrical investigation into the inheritance of flowering time and final height in $\mathcal{N}$. rustica has been carried out over a period of three successive years by means of recurrent backcross generations derived from the two inbred varieties $I$ and 5 .

Both characters are subject to environmental and non-allelic interactions, though there is evidence suggesting that height is less susceptible to them than flowering time. From the components of generation means it is clear that the genes controlling both characters show additivity and dominance, whilst for flowering time the genes concerned exhibit duplicate type interactions. The genetic picture which emerges from both the weighted and unweighted estimations of the components of variation is predominantly one of additivity. Despite the prevalence of interactions there is reasonable evidence for dominance amongst the genes controlling height, and likewise for breakable repulsion linkages between those genes concerned with the expression of flowering time.

A comparative study of the recurrent backcross and $F_{2}$ selfing series approaches from a biometrical standpoint indicates that, technical considerations apart, the former is to be preferred on the grounds of greater experimental efficiency. However, this design is not by any means the most efficient attainable, and an alternative is suggested which should in theory supply valuable information on many of the problems encountered in investigations of continuous variation.

\footnotetext{
Acknowledgments.-I wish to express my thanks to Mr R. Morley Jones for the time he devoted to the preparation of the data in a form suitable for processing by computer, and for his help in interpreting the results of the weighted analyses. I am also indebted to Professor K. Mather, D.Sc., F.R.S., and Dr J. L. Jinks, D.Sc., for their helpful advice and criticism. Finally, I am grateful to Mr G. W. Bonsall and Mr G. J. S. Ross, of the Rothamsted Experimental Station and to the Director of the Computing Laboratory, Manchester University for providing time on their respective computers.

This work has been carried out whilst in receipt of an Agricultural Research Council Studentship.
}

\section{REFERENCES}

BREESE, E. L. 1954. Continuous variation in higher plants. Ph.D. Thesis, Birmingham.

GAVALLI, L. L. 1952. An analysis of linkage in quantitative inheritance. Quantitative Inheritance. H.M.S.O., London. pp. 135-144. 
GOOKe, P., MORLey JONes, R., MATHER, K., BONSAll, G. W., AND NELder, J. A. I962. Estimating the components of continuous variation. I. Statistical. Heredity, $r 7, I^{1} 5^{-1} 33$.

HAYMAN, B. I., AND MATHER, K. I955. The description of genic interactions in continuous variation. Biometrics, $I 1,69-82$.

JINKs, J. L. I955. A survey of the genetical basis of heterosis in a variety of diallel crosses. Heredity, 9, 223-238.

JiNks, J. L. 1956. The $\mathrm{F}_{2}$ and backcross generations from a set of diallel crosses. Heredity, IO, I-3o.

JINKS, J. L., AND MATHER, K. I955. Stability in development of heterozygotes and homozygotes. P.R.S., B, $r_{43}, 56 \mathrm{I}-578$.

JINKS, J. L., AND MORLEY JONES, R. 1958. Estimation of the components of heterosis. Genetics, 43, 223-234.

MATHER, K. I 949 . Biometrical Genetics. Methuen \& Co., London.

MATHER, K., AND VINES, A. 1952. The inheritance of height and flowering time in a cross of Nicotiana rustica. Quantitative Inheritance. H.M.S.O., London, pp. 49-79.

NELDER, J. A. 1960. The estimation of variance components in certain types of experiment on quantitative genetics. Biometrical Genetics, ed. O. Kempthorne. Pergamon Press, pp. I $39-5^{8}$.

OPSAHL, B. I956. The discrimination of interactions and linkage in continuous variation. Biometrics, 12,4 5 5-432.

VAN DER VEEN, J. H. I959. Tests on non-allelic interaction and linkage for quantitative characters in generations derived from two diploid pure lines. Gentica, 30, $201-232$. 